Article

\title{
Life Cycle Assessment on Different Synthetic Routes of ZIF-8 Nanomaterials
}

\author{
Vasileios Ntouros ${ }^{1, *(D)}$, Ioannis Kousis ${ }^{2,3}$, Dimitra Papadaki ${ }^{1}$ (D) Anna Laura Pisello ${ }^{2,3}$ (D) \\ and Margarita Niki Assimakopoulos ${ }^{1}$ (D) \\ 1 Group Building Environmental Research, Department of Physics, National and Kapodistrian \\ University of Athens, University Campus, 15784 Athens, Greece; dpapadaki@phys.uoa.gr (D.P.); \\ masim@phys.uoa.gr (M.N.A.) \\ 2 CIRIAF, Interuniversity Research Center, University of Perugia, Via G. Duranti 67, 06125 Perugia, Italy; \\ ioannis.kousis@unipg.it (I.K.); anna.pisello@unipg.it (A.L.P.) \\ 3 Department of Engineering, University of Perugia, Via G. Duranti 97, 06125 Perugia, Italy \\ * Correspondence: vntouros@phys.uoa.gr
}

Citation: Ntouros, V.; Kousis, I.;

Papadaki, D.; Pisello, A.L.;

Assimakopoulos, M.N. Life Cycle Assessment on Different Synthetic Routes of ZIF-8 Nanomaterials. Energies 2021, 14, 4998. https:// doi.org/10.3390/en14164998

Academic Editor: João

Fernando Pereira Gomes

Received: 10 June 2021

Accepted: 4 August 2021

Published: 14 August 2021

Publisher's Note: MDPI stays neutral with regard to jurisdictional claims in published maps and institutional affiliations.

Copyright: (c) 2021 by the authors. Licensee MDPI, Basel, Switzerland. This article is an open access article distributed under the terms and conditions of the Creative Commons Attribution (CC BY) license (https:/ / creativecommons.org/licenses/by/ $4.0 /)$.

\begin{abstract}
In the last twenty years, research activity around the environmental applications of metalorganic frameworks has bloomed due to their $\mathrm{CO}_{2}$ capture ability, tunable properties, porosity, and well-defined crystalline structure. Thus, hundreds of MOFs have been developed. However, the impact of their production on the environment has not been investigated as thoroughly as their potential applications. In this work, the environmental performance of various synthetic routes of MOF nanoparticles, in particular ZIF-8, is assessed through a life cycle assessment. For this purpose, five representative synthesis routes were considered, and synthesis data were obtained based on available literature. The synthesis included different solvents (de-ionized water, methanol, dimethylformamide) as well as different synthetic steps (i.e., hours of drying, stirring, precursor). The findings revealed that the main environmental weak points identified during production were: (a) the use of dimethylformamide (DMF) and methanol $(\mathrm{MeOH})$ as substances impacting environmental sustainability, which accounted for more than $85 \%$ of the overall environmental impacts in those synthetic routes where they were utilized as solvents and as cleaning agents at the same time; (b) the electricity consumption, especially due to the Greek energy mix which is fossil-fuel dependent, and accounted for up to $13 \%$ of the overall environmental impacts in some synthetic routes. Nonetheless, for the optimization of the impacts provided by the energy use, suggestions are made based on the use of alternative, cleaner renewable energy sources, which (for the case of wind energy) will decrease the impacts by up to $2 \%$.
\end{abstract}

Keywords: ZIF-8; metal organic frameworks; life cycle analysis; environmental impact assessment; nanomaterials; synthesis procedure

\section{Introduction}

Nanoscience, due to its disruptive, enabling, and interdisciplinary nature [1], has the potential to stimulate scientists across different fields to meet the major challenges in relation to environmental sustainability [2]. This became apparent over the last decade, as hundreds of porous nanomaterials targeted for efficient energy utilization [3], energy conversion and storage [4], gas separation [5], as well as for carbon capture and storage [6,7] have been reported as a response to the emerging climate change. However, in seeking environmental sustainability, nanomaterials deployed to mitigate global warming should not only be evaluated based on their operational efficiency, but should also be assessed in terms of their carbon dioxide emissions and overall environmental impact during their production. Therefore, in terms of carbon negativity a porous material used for carbon dioxide removal must capture higher amounts of $\mathrm{CO}_{2}$ than those released in the atmosphere during its production while at the same time, it should not put extra pressure to 
the environment. Otherwise, this process of atmospheric decarbonisation is unsustainable. As a result, the assessment of the environmental impact during the production phase, i.e., synthesis, of porous materials is a key element that enables the identification of eco-friendly synthetic routes.

In this work, the environmental assessment of different synthesis procedures for the fabrication of ZIF-8 nanomaterials has been investigated. These nanomaterials provide sustainable solutions for the capture of gaseous $\mathrm{CO}_{2}$ and can be widely applied in several sectors, such as the building industry and urban environments, for the abatement of climate change. Nonetheless for the overall assessment of these nanomaterials, a complete life cycle analysis must be considered in order to estimate the overall impacts of the materials during the construction phase, as well as to identify the environmental hotspots of each synthetic route to provide future suggestions to the research community on a more sustainable production of these nanomaterials.

In the last twenty years, research activity around the class of porous coordination polymers, widely known as metal-organic frameworks (MOFs) has bloomed thanks to their porosity, stability, and ordered crystalline structure [8]. MOFs are a special class of porous nanomaterials, comprised by organic ligands attached to metallic ions via coordination bonds forming open crystalline frameworks with permanent porosity [8-10]. Their tunable properties make them beneficial for applications in various sectors, e.g., the building sector [11], transportation [12], or even the food sector [13]. In recent years, a MOF that has attracted interest is $\mathrm{ZIF}-8(\mathrm{Zn}(\mathrm{mIM}) 2, \mathrm{mIM}=2$-methylimidazolate $)$ as a result of its high surface areas, controllable structures and adjustable size of their pores [14]. It belongs to the group of zeolitic imidazolate frameworks, a branch of the MOFs family, and shows exceptional chemical and thermal stability [15-18] which makes it a favorable candidate for various applications $[19,20]$.

\subsection{ZIF-8 Applications}

The ZIF-8 porous membranes are considered as promising materials for several applications such as gas separation, photocatalysis, sensing and electronic devices and drug delivery systems [21]. ZIF-8 is hydrophobic and the size of their pore is approximately $0.34 \mathrm{~nm}$. Therefore, it is considered as a good candidate for separation techniques concerning $\mathrm{H}_{2}$ within large gas molecules and $\mathrm{C}_{2}-\mathrm{C}_{3}$ hydrocarbon mixtures. Moreover, it has been reported to demonstrate good performance in vapor separation with respect to biofuel recovery applications. Hwang et al. [22] developed hollow zeolite imidazole frameworks nanoparticles (H_ZIF-8) and used them as fillers in order to improve the permeability of mixed matrix membranes for $\mathrm{CO}_{2} / \mathrm{CH}_{4}$ gas separation. Roberto et al. synthesized ZIF-8-based mixed-matrix membranes and reported excellent $\mathrm{CO}_{2} / \mathrm{CH}_{4}$ separation performance [23]. Similarly, Julien et al. found that the implementation of ZIF-8 membranes can efficiently separate biobutanol from aqueous solution in the presence of other contaminants [24].

ZIFs bear a close resemblance to aluminosilicate zeolites, i.e., widely used catalysts. Therefore, ZIFs are also investigated for catalytic applications. In fact, ZIF-8 are reported an efficient heterogeneous catalyst for several reaction such as the Knoevenagel reaction, transesterification reaction of vegetable oils, the Friedel-Crafts acylation reaction, the reaction between styrene oxide and carbon dioxide, as well as epoxidation and oxidation reactions. For instance, Xue et al. showed that ZIF-8 can be a good catalyst for oxygen reduction reaction in microbial fuel cell [25], while Zhu et al. reported a good catalytic performance with respect to the styrene oxide-carbon dioxide reaction [26]. Olaniyan and Saha prepared a Zr-doped ZIF-8 catalyst to synthesize organic carbonates by utilizing $\mathrm{CO}_{2}$ [27]. ZIF-8 is also utilised for $\mathrm{CO}_{2}$ greenhouse gas adsorption, since its aperture has a size of approximately $0.34 \mathrm{~nm}$, which approximates the nominal kinetic diameter of $\mathrm{CO}_{2}$. Under this scenario, Cardoso et al. fabricated a MOF by depositing ZIF- 8 on $\mathrm{TiO}_{2}$ nanotubes for a photo-electrocatalytic applications [28]. The resultant system was found to reduce $\mathrm{CO}_{2}$ reactions in aqueous solutions under room temperature. In general, ZIF- 8 combined 
with materials such as $\mathrm{Au}, \mathrm{Ag}, \mathrm{Pt}, \mathrm{Ru}$, and $\mathrm{Pd}$ nanoparticles are reported for catalytic applications with respect to the oxidation of $\mathrm{CO}$, the aldehyde groups, hydrogen of $\mathrm{n}$ hexene or alkene, aminocarbonylation, or the asymmetric hydrogenation of acetophenone, among other. Similarly, Huang et al. coupled a $\mathrm{TiO}_{2}$ grid-like film with ZIF-8 which was found to highly capture $\mathrm{CO}_{2}$ and consequently reduce $\mathrm{CO}_{2}$ to $\mathrm{CO}$ and $\mathrm{CH}_{4}$ [29]. Chang et al. nanoconfined the metal oxides of $\mathrm{MgO}$ and $\mathrm{ZnO}$ in zeolitic imidazolate framework ZIF-8 and reported improved $\mathrm{CO}_{2}$ uptake, high $\mathrm{CO}_{2}$ adsorption capacity, fast $\mathrm{CO}_{2}$ adsorption kinetics at room temperature, and reduced decarbonation temperature [30]. Khan et al. reported a fabrication methodology for ZIF-8 in an aqueous solution at ambient temperature [31]. The resultant structure was characterized by a rather low molar ratio of $\mathrm{Zn}^{+2} / \mathrm{Hmim}(1: 8)$ and small particle size. Moreover, its porosity, thermal stability, and $\mathrm{CO}_{2}$ desorption capability were improved. The $\mathrm{CO}_{2}$ desorption capacity was further enhanced after ammonia modification by implementing ammonium hydroxide solution.

Recently, the application of ZIF-8 to sensors and electronic technologies has attracted the interest of the research community. The high textural properties, in conjunction with the tunable pore diameter and the relatively easy functionalization, make ZIF-8 ideal for chemical sensing, low dielectric constant applications, and biosensor construction. Yang et al. fabricated a fluorescent chemical nanoprobe sensor for alcohols by encapsulating HDBB molecules into the nanochannel of ZIF-8 [32]. Zhan et al. developed a polyhedral ZIF-8 nanostructures by applying a solvothermal method and reported excellent $\mathrm{NO}_{2}$ gassensing, while Matatagui developed a chemoresistive gas sensor by merging nanostructures of ZIF-67 and ZIF-8 [33,34]. Lin et al. encapsulated branched poly-(ethylenimine)-capped carbon quantum dots (BPEI-CQDs) characterized by high FL quantum yield into ZIF-8. The outcomes of their study suggest that the resultant structure can be an efficient selective sensor for $\mathrm{Cu}^{2+}$ ions [35].

At the same time, ZIF-8 is investigated for drug delivery systems and controlled drug release applications owing to its excellent thermo-chemical stability, tunable functionality in the frameworks, and its intrinsic properties of $\mathrm{pH}$-sensitive release. Sun et al. were the first to investigate ZIF-8 as a drug delivery component owing to its $\mathrm{pH}$-sensitive dissolution property [36]. Vasconcelos et al. incorporated the anti-cancer drug doxorubicin into ZIF8 and reported a substantial loading capacity for the anticancer drug 5-fluorouracil [37]. He et al. presented a simple two-step method for fabricating green, fluorescent carbon nanodots@zeolitic imidazolate framework-8 nanoparticles (C-dots@ZIF-8 NPs) [38]. The resulted structure has tunable size and fluorescence intensity. Therefore, ZIF- 8 is reported as ideal for $\mathrm{pH}$-responsive drug delivery systems, while it can also be utilized for the fluorescence imaging of cancer cells.

\subsection{Life Cycle Assessment of Nanomaterials}

In one research work, the effect of different synthesis procedures and several deprotonators was investigated. The morphology, surface area, and thermal stability, together with the life cycle assessment (LCA) were investigated. ZIF-8 from recycled starting material was synthesized using $\mathrm{NH}_{4} \mathrm{OH}$ and $\mathrm{NaOH}$. It was proven that the use of recycled mother liquors decreased the amount of solvent that was used for cleaning, thus leading to a more sustainable process. More specifically, when $\mathrm{NH}_{4} \mathrm{OH}$ was used, the environmental impacts were less, in comparison to the process when $\mathrm{NaOH}$ was used [39]. Luo et al. assessed the environmental and economic performance of two different routes for $\mathrm{UiO}-66-\mathrm{NH}_{2}$ synthesis concluding that the water-based product has significant environmental benefits [40]. In another study, MOF materials were assessed via a cradle-to-gate life-cycle assessment of four different synthesis protocols. It was found that the environmental impacts of using solvents in the synthesis or for cleaning and purification purposes is considerable. Therefore, it was concluded that, ideally, the use of solvents should be avoided, otherwise reutilization processes should be further studied for future applications. In the same study, water was used as a solvent during synthesis. With this solvent, it was proven that the $\mathrm{CO}_{2}$ emissions, freshwater toxicity, and resource depletion were all highly reduced [41]. In another study, 
using LCA in nanotechnology, results showed that the stage that is dominated by the environmental impacts is associated to energy and chemical use in the synthesis process of the nanotechnology fabrication. Moreover, this work highlights the two main challenges faced by similar works, namely the non-comparability of the available reports and the lack of available data for the synthesis route of the materials. Moreover, their disposal/recycling potential can be complicated and needs future investigation [42].

In a study conducted by Sendão et al. in 2020 a LCA approach was used for the comparison of the environmental impacts of carbon dots (CDs) from six synthetic routes. These routes included both microwave and hydrothermal methods. Results show that for hydrothermal synthesis the use of electricity is dominant, while citric acid produces most impacts for microwave-assisted synthesis [43]. In research conducted by Papadaki et al. in 2017, LCA was applied as a useful tool for the environmental assessment of $\mathrm{ZnO}$ nanomaterials since it presents the environmental hotspots of different synthesis steps or processes. From this research, it was found that the use of ethanol for purifying purposes and the electricity consumption for the calcination of $\mathrm{ZnO}$, as provided by South Africa's fossil fuel electricity mix, were the main environmental hotspots identified during the production process [44].

Nonetheless, in comparison to the long available research conducted in the field of nanotechnology, the LCA methodology has been relatively scarcely applied. LCA is a comprehensive tool which is used to assess the environmental sustainability of a product or system and provides environmental considerations for decision and policy makers, as well as for the research community [45]. According to authors' best knowledge the environmental sustainability of different synthetic routes of ZIF-8 nanomaterials remains a missing element from the existing literature.

In this work, an LCA of five different ZIF-8 synthetic routes is presented, considering $1 \mathrm{~kg}$ of produced powder of ZIF- 8 as the functional unit. The objective of this work is to present the impact of synthesis using different solvents [water, dimethylformamide (DMF), methanol] and cleaning procedures, aiming to investigate the most environmentally friendly synthesis route, as well as to highlight the environmental hotspots identified in the assessment. In addition, a sensitivity analysis in terms of energy sources is undertaken for the most environmentally impactful synthesis, where different energy sources (Greek energy mix, wind, and solar renewable energy sources) were investigated.

\section{Materials and Methods}

LCA is a tool widely used for assessing, characterizing, and evaluating the overall environmental footprint of the investigated product, system, or processes. It is an objective procedure that quantifies the energy and the environmental loads related to specific procedures or activities followed throughout the various life-steps of a product. LCA analysis takes into account all (or partial) step-phases of the life cycle of the product and evaluate them accordingly: The three main LCA assessments are the following: (i) The cradle-tograve approach defined by the Society of Environmental Toxicology and Chemistry [45] that takes into account the entire life-cycle of the product. (ii) The cradle-to-gate approach considers life-cycle phases up to when the product leaves the factory gates. It reduces the complexity of the LCA analysis and is regularly preferred when there is lack of available data, e.g., due to the innovativeness of novel materials [46]. (iii) The cradle-to-cradle approach (also referred to as "closed-loop recycling") is a variation of the cradle-to-grave approach that replaces the waste disposal phase with a recycling phase through which the waste product can be re-used for another application. It is regularly used under the framework of the circular economy.

The LCA study presented in this work follows a cradle-to-gate methodology, from the production to the fabrication of the ZIF- 8 materials. The environmental performance of these synthesis routes was examined by means of the LCA methodology as determined in ISO 14040:2006 and ISO 14044:2006 [47]. Environmental impacts were modelled applying the ReCiPe 2016 v1.01 LCIA, Hierarchist version extracted from the database Ecoinvent [48]. 
The main goal of the ReCiPe methodology is to translate a list of life cycle inventory outcomes, into a few indicator scores, that express the damages related to an environmental impact category. In the ReCiPe method, 18 indicators are set out at midpoint level and 3 indicators at endpoint level [49]. Midpoint indicators are related to product stages, such as the extraction and production of the materials, and the endpoint indicators demonstrate the environmental impact on a higher aggregation level comprising three main categories, i.e., the effect on human health, biodiversity, and resource scarcity. The impact potentials evaluated at midpoint level according to the ReCiPe method were: global warming, stratospheric ozone depletion, ionization radiation, ozone formation - human health, fine particulate matter formation, ozone formation - terrestrial ecosystems, terrestrial acidification, freshwater eutrophication, marine eutrophication, terrestrial ecotoxicity, freshwater ecotoxicity, marine ecotoxicity, human carcinogenic toxicity, human non-carcinogenic toxicity, land use, mineral resource scarcity, and water consumption. The aggregation of the midpoint scores and their conversion to endpoint counterparts may simplify the interpretation of the LCIA, but at the same time may be prone to uncertainty biases. Therefore, in the present study, both midpoint and endpoint indicator scores are retrieved and evaluated. Furthermore, the outcomes at both midpoint and endpoint level can be interpreted according to three main cultural perspectives, i.e., (i) individualist- optimistic perspective considering short term impacts due to main chemicals, (ii) egalitarian-precautionary perspective considering long term impacts and involving risks, and (iii) hierarchism-consensus perspective based on main policy principles, which is generally recommended and therefore adopted in the present study. In addition, this LCA study was conducted by using the SimaPro 8.5.2. software. Sensitivity analysis was also conducted, considering two different energy sources, i.e., solar power and wind power, for the fabrication of these materials, corresponding to different environmental impacts.

\subsection{Goal and Scope}

The goal of the present analysis is to examine the environmental impact of various synthesis routes of ZIF-8 nanomaterials. Five different synthetic approaches to produce ZIF- 8 are taken into account and comparative assessment was developed. The functional unit is $1 \mathrm{~kg}$ of ZIF- 8 material. This stands as the reference point of normalization for inputs and outputs, quantifying the product system's performance [50]. The system boundaries of this work, illustrated in Figure 1, are limited in the synthesis process of the material and determine which processes, in terms of materials, power inputs, and procedures, are considered for the study and does not account for any possible application of the material (e.g., carbon dioxide removal). Therefore, this analysis adopts a "cradle to gate" approach.

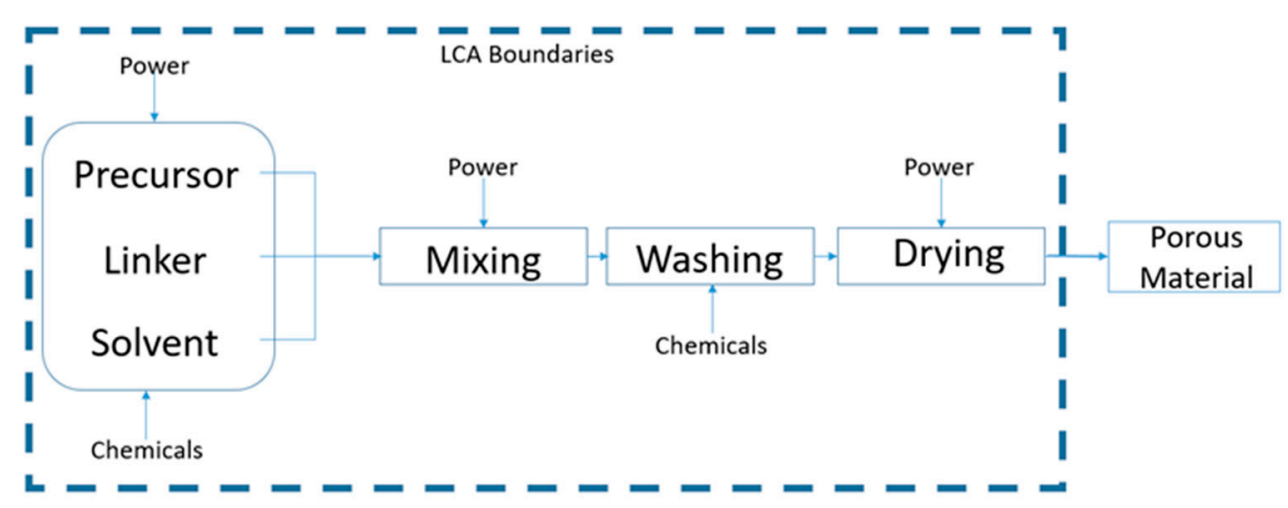

Figure 1. The LCA boundaries of the study.

\subsection{Life Cycle Inventory Analysis}

Five different synthetic routes were obtained from the literature, incorporating three most frequently used solvents (methanol, DMF, and water) for the preparation of ZIF-8. Synthesis 1 is adopted from Şahin et al. [51], Synthesis 2 from Kida et al. [52]. Synthesis 
3 and 4 were adopted from Lee et al. [53], and Synthesis 5 from Tsai et al. [54]. Table 1 summarizes the amounts of mass per chemical input required for this work based on the aforementioned synthetic procedures.

Table 1. Details of the synthetic routes for the production of $1 \mathrm{~kg}$ ZIF-8.

\begin{tabular}{|c|c|c|c|c|c|c|c|c|}
\hline \multirow[b]{2}{*}{ Synthesis } & \multirow[b]{2}{*}{$\begin{array}{l}\text { Precursor } \\
\quad(\mathrm{kg})\end{array}$} & \multirow{2}{*}{$\begin{array}{l}\text { Mass } \\
\text { Linker } \\
(\mathbf{k g})\end{array}$} & \multirow[b]{2}{*}{$\begin{array}{l}\text { Solvent for Synthesis } \\
\text { (kg) }\end{array}$} & \multirow{2}{*}{$\begin{array}{l}\text { Solvent for } \\
\text { Washing } \\
\text { (kg) }\end{array}$} & \multicolumn{2}{|c|}{ Energy } & \multirow[b]{2}{*}{ Yield (\%) } & \multirow[b]{2}{*}{$\begin{array}{l}\text { BET Surface } \\
\text { Area }\left(\mathrm{m}^{2} / \mathrm{g}\right)\end{array}$} \\
\hline & & & & & $\begin{array}{l}\text { Electricity } \\
(\mathrm{kWh})\end{array}$ & $\begin{array}{l}\text { Heat } \\
\text { (MJ) }\end{array}$ & & \\
\hline 1 & $\begin{array}{c}\mathrm{Zn}\left(\mathrm{NO}_{3}\right)_{2} 6 \mathrm{H}_{2} \mathrm{O} \\
1.921\end{array}$ & 37.274 & 144.5 De-Ionized water & $19.5 \mathrm{MeOH}$ & 12.2 & 60.25 & 68 & 1424 \\
\hline 2 & Zn 1.465 & 24.213 & 196.85 De-Ionized water & $70.08 \mathrm{MeOH}$ & 23.4 & 73.03 & 89.6 & 1600 \\
\hline 3 & $\begin{array}{c}\mathrm{Zn}\left(\mathrm{NO}_{3}\right)_{2} 6 \mathrm{H}_{2} \mathrm{O} \\
4.8\end{array}$ & 1.2 & $\begin{array}{l}341.3 \text { dimethylformamide } \\
\text { (DMF) }\end{array}$ & $\begin{array}{c}\text { 205.2 DMF } \\
113.8 \mathrm{MeOH}\end{array}$ & 23.2 & 86.3 & 60 & 1370 \\
\hline 4 & $\begin{array}{c}\mathrm{Zn}\left(\mathrm{NO}_{3}\right)_{2} 6 \mathrm{H}_{2} \mathrm{O} \\
6.732\end{array}$ & 1.678 & $636 \mathrm{MeOH}$ & $357.7 \mathrm{MeOH}$ & 11.8 & 278.5 & 43 & 1549 \\
\hline 5 & $\begin{array}{c}\mathrm{Zn}\left(\mathrm{NO}_{3}\right)_{2} 4 \mathrm{H}_{2} \mathrm{O} \\
2.367\end{array}$ & 6.33 & $432.5 \mathrm{MeOH}$ & $649.6 \mathrm{MeOH}$ & 2.3 & 580.7 & 48 & 1605 \\
\hline
\end{tabular}

For the synthetic procedures in which specific details were missing, assumptions were imposed. Furthermore, it was assumed that typical laboratory equipment was used for the production of ZIF-8, namely a simple stirrer (36 W) in Synthesis 1-3, a hot plate stirrer $(600 \mathrm{~W})$ in Synthesis 5, and a refrigerated centrifugator $(750 \mathrm{~W})$ and a convection oven $(1200 \mathrm{~W})$ in all syntheses. In cases where the time of stirring (Synthesis 2 and 3) or the time of centrifugation (Synthesis 4) was not indicated, $30 \mathrm{~min}$ was assumed as the time of stirring or centrifugation. At last, the time needed for the activation of the product in Synthesis 5 was assumed to be $90 \mathrm{~min}$. The aforementioned assumptions regarding amounts of mass and time considered in this work are based on common synthetic procedures reported in the literature. Finally, since there are no data available on ZIF-8 scale up industrial processes to produce $1 \mathrm{~kg}$ of ZIF-8, the methodology followed for the calculation of energy demand for the synthesis of $1 \mathrm{~kg}$ of ZIF-8 is based on the work of Luo et al. [40].

The stirrer, the centrifugator, the oven, and the vials, as materials, are not included within the system's boundaries, whereas the energy they consume (electricity) is included within the system's limits. In addition, this study covers Greece, and thus the electric energy consumed is presumed to originate from Greece's infrastructure. Fossil fuels, with coal and oil being on the top, are predominant in Greece's electricity mix [55].

\section{Results}

For the assessment of the five synthetic routes, an LCA was conducted and findings are presented in Table 2 and Figures 2 and 3. The main differences between these five approaches as also seen in Table 1, are the solvents and the amount of materials used in the synthetic procedure. Syntheses 1 and 2 utilize de-ionized water as a solvent, while in Synthesis 3 DMF is used as the solvent, and in Syntheses 4 and 5, methanol. According to the damage assessment (Figure 2), the most impactful synthesis to the environment is Synthesis 3, which utilizes DMF as a solvent and DMF/MeOH for cleaning the product. Moreover, as seen from the characterization results (Figure 3), the 3rd synthetic route has the biggest impacts, in all 18 impact indicators. On the contrary, in Synthesis 1, by significantly reducing the energy consumption, almost eliminating the utilization of chemicals in the cleaning step and following an aqueous based route to synthesize ZIF8 , a reduction of $95 \%$ of the impact on the ecosystems, $94 \%$ on human health, and $93 \%$ on resources is observed and depicted in Figure 2. Overall, a significant reduction in all 18 impact categories has been attained by following a free from solvent synthesis, by reducing the use of solvents in the washing step, and decreasing the energy requirements of the production process. Particularly, the highest environmental impacts are found in Synthesis 3, followed by Synthesis 5, with a 52\% reduction of their impact with regard to human health, $54 \%$ to ecosystems, and a $12 \%$ reduction with regard to resources; Synthesis 
4 , with a $58 \%$ reduction with regard to human health, $56 \%$ to ecosystems, and a $20 \%$ reduction with regard to resources; Synthesis 2, with a reduction greater than $90 \%$ in all three categories; and Synthesis 1 with a reduction greater than $93 \%$ in relation to all the environmental impacts.

Table 2. Life Cycle Assessment of five different synthetic routes to produce ZIF-8.

\begin{tabular}{|c|c|c|c|c|c|c|}
\hline Impact Category & Unit & Synthesis 1 & Synthesis 2 & Synthesis 3 & Synthesis 4 & Synthesis 5 \\
\hline Global warming & $\mathrm{kg} \mathrm{CO} 2 \mathrm{eq}$ & 86.60 & 125.65 & 1571.16 & 782.57 & 858.25 \\
\hline Stratospheric ozone depletion & kg CFC11 eq & 0.00 & 0.00 & 0.00 & 0.00 & 0.00 \\
\hline Ionizing radiation & $\mathrm{kBq}$ Co-60 eq & 4.41 & 3.80 & 167.78 & 16.02 & 17.78 \\
\hline Ozone formation, Human health & $\mathrm{kg} \mathrm{NO}_{\mathrm{x}} \mathrm{eq}$ & 0.13 & 0.20 & 2.76 & 1.51 & 1.67 \\
\hline Fine particulate matter formation & $\mathrm{kg}$ PM2.5 eq & 0.16 & 0.22 & 2.21 & 0.82 & 0.89 \\
\hline $\begin{array}{l}\text { Ozone formation, Terrestrial } \\
\text { ecosystems }\end{array}$ & $\mathrm{kg} \mathrm{NO}$ eq & 0.14 & 0.21 & 2.90 & 1.60 & 1.78 \\
\hline Terrestrial acidification & $\mathrm{kg} \mathrm{SO}_{2} \mathrm{eq}$ & 0.41 & 0.60 & 5.88 & 2.19 & 2.36 \\
\hline Freshwater eutrophication & $\mathrm{kg} \mathrm{P} \mathrm{eq}$ & 0.01 & 0.02 & 0.55 & 0.14 & 0.15 \\
\hline Marine eutrophication & $\mathrm{kg} \mathrm{N} \mathrm{eq}$ & 0.00 & 0.00 & 1.67 & 0.01 & 0.01 \\
\hline Terrestrial ecotoxicity & $\operatorname{kg} 1,4-\mathrm{DCB}$ & 259.42 & 719.13 & 5798.03 & 1484.69 & 1236.89 \\
\hline Freshwater ecotoxicity & kg 1,4-DCB & 1.34 & 2.68 & 46.13 & 16.13 & 16.91 \\
\hline Marine ecotoxicity & kg 1,4-DCB & 2.07 & 4.29 & 64.58 & 23.80 & 24.72 \\
\hline Human carcinogenic toxicity & $\mathrm{kg} \mathrm{1,4-DCB}$ & 1.37 & 2.02 & 47.61 & 13.51 & 14.79 \\
\hline Human non-carcinogenic toxicity & kg 1,4-DCB & 53.88 & 125.85 & 1399.89 & 557.56 & 559.70 \\
\hline Land use & $\mathrm{m}^{2} \mathrm{a}$ crop eq & 1.14 & 1.43 & 29.95 & 7.30 & 10.25 \\
\hline Mineral resource scarcity & kg Cu eq & 0.30 & 0.80 & 5.12 & 2.24 & 2.02 \\
\hline Fossil resource scarcity & kg oil eq & 61.32 & 87.21 & 962.58 & 775.49 & 851.39 \\
\hline Water consumption & $\mathrm{m}^{3}$ & 0.72 & 0.92 & 23.81 & 4.98 & 5.43 \\
\hline
\end{tabular}

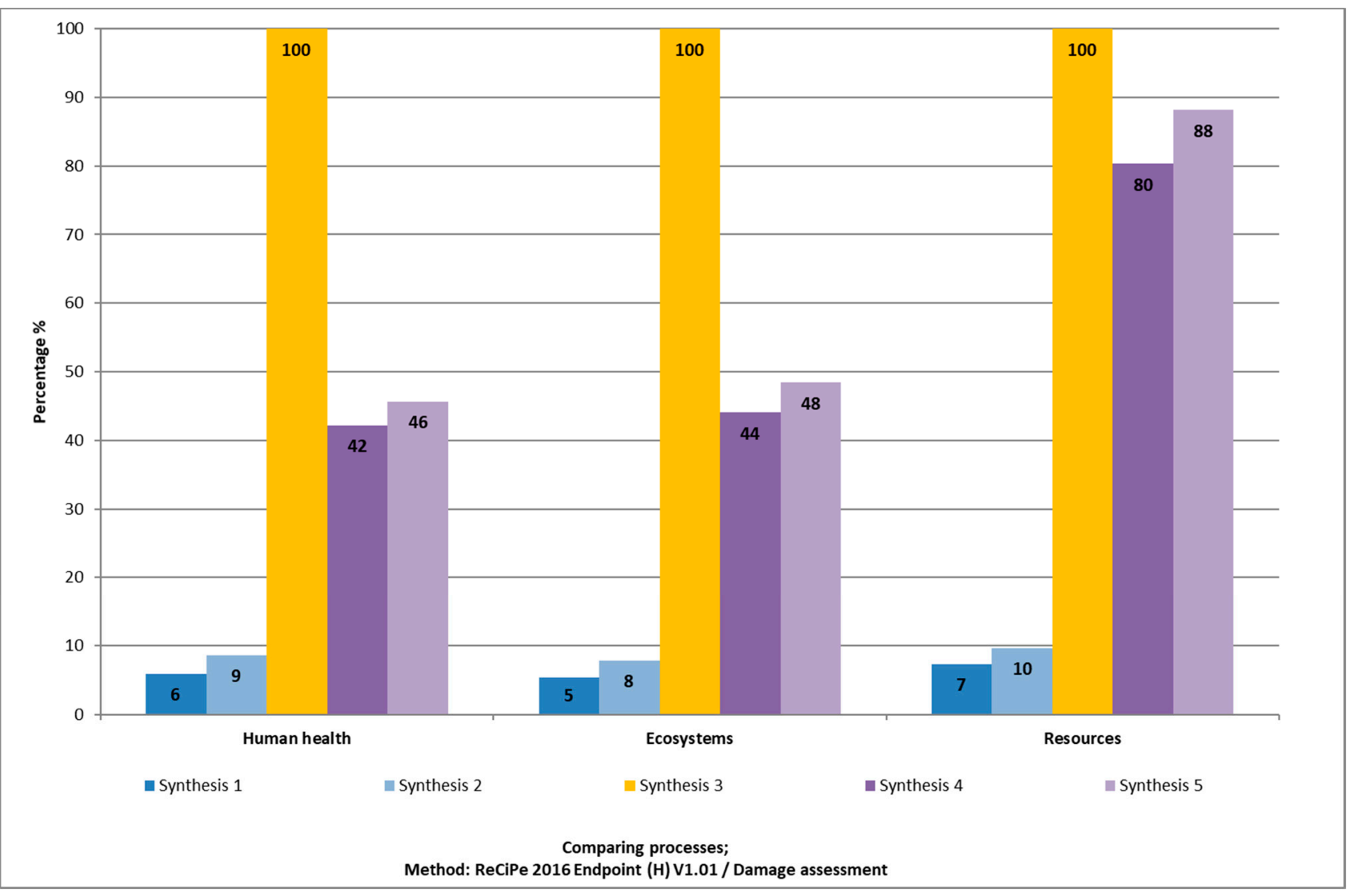

Figure 2. Comparative damage assessment of the five synthetic routes of ZIF-8. 


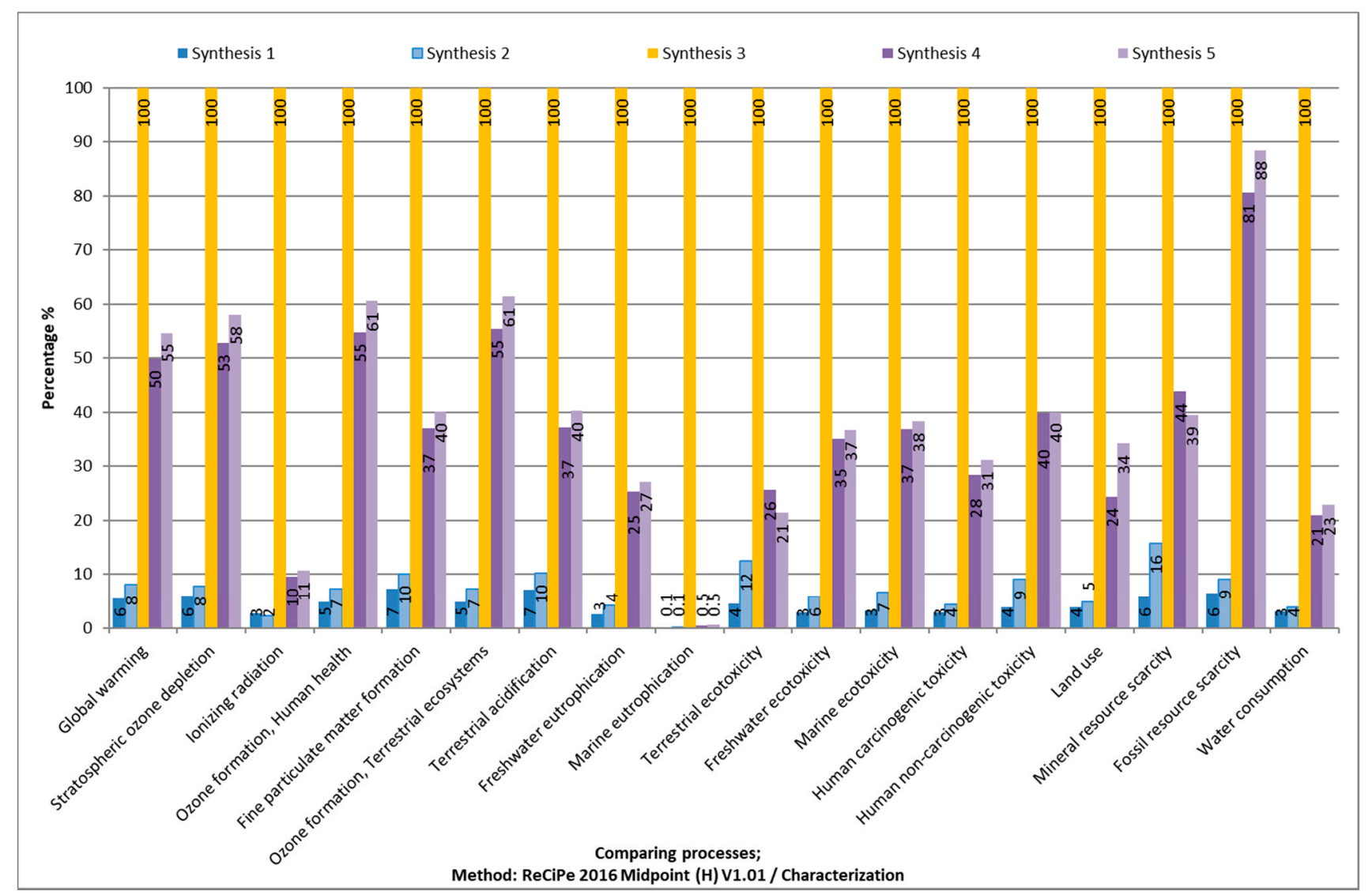

Figure 3. Comparison of the five ZIF-8 synthetic routes per impact category.

All the comparative reductions are shown in Figures 2 and 3, as percentage reduction per indicator, after the normalization of the results.

Comparing the three most impactful synthetic routes in respect of environmental sustainability, Syntheses 3, 4, and 5, we can conclude that Synthesis 4 is less impactful as it requires less energy and methanol than Synthesis 5. With regard to Synthesis 3, the amount of electric energy required which originates from lignite sources and the utilization of high amounts of DMF brings it on the top as the most impactful synthesis. These three synthetic approaches explored are the most impactful to the environment compared to the other two, as they require the greatest amounts of energy for the production of $1 \mathrm{~kg}$ ZIF-8, whereas they utilize organic solvents in their synthetic procedure, methanol and DMF, instead of water as for Synthesis 1 and 2. The solvents employed in the synthesis procedures may coordinate with metal ions or they may fill space in the final lattice frame acting as a guest molecule [56]. Solvents such as DMF play a critical role in the crystal growth of the porous material, i.e., in controlling the length of deprotonation of organic carboxylate ligands, but in order to drive carboxylates' deprotonation the solvent should be transformed to its equivalent amines, a process that requires higher temperatures [57] In addition, DMF as a guest molecule, due to its higher kinetic diameter than methanol, cannot be removed as easily as methanol from the pore network of the material, whereas water molecules, being smaller than the pores of ZIF-8, can be removed more easily [52]. Furthermore, some of the solvent ligands are demonstrate low volatility (e.g., DMF in contrast to methanol), and therefore require a high temperature (or long evacuation times if pressure is applied) in order to be removed from the final MOF lattice structure [56]. In terms of environmental impact, this behavior of chemical solvents is depicted in results with adverse effects on the overall sustainability of the Syntheses 3-5 compared to the first two. Avoiding harmful solvents also makes the whole synthetic procedure safer to humans and more cost effective. 
However, as illustrated in percentage points in Figure 3 and depicted in absolute numbers in Table 2, when comparing Synthesis 3 with Synthesis 2, it is observed that the environmental impact of ZIF-8 is dependent not only on the consumed energy, but it is also strongly dependent on the amount and type of the solvents used. The 3rd synthetic approach, in spite of demanding almost equal amounts of energy, requires a chemical solvent for the production of the material and higher amounts of solvents for the cleaning process than the 2nd synthetic route. As a result, Synthesis 2, due to the slightly decreased energy required, but mainly due to the utilization of de-ionized water as a solvent, shows reduced environmental impacts, in comparison to Synthesis 3, in all 18 impact categories.

Based on the results, the best synthetic approach is found to be Synthesis 1, with an overall impact of being reduced by more than approximately $93 \%$ compared to the most impactfull synthetic route, Synthesis 3 . It shows a significantly lower impact on the environment as it requires de-ionized water as a solvent instead of an organic solvent (DMF or methanol), the least amount of solvent for cleaning the material, and the least amount of energy for the production of $1 \mathrm{~kg}$ ZIF-8, as calculated based on the reported initial yield of the synthesis (Table 1).

Overall, the energy consumption for the synthesis of ZIF-8 required in some synthetic approaches not only affects the traditional impact category of "Global warming" due to $\mathrm{CO}_{2}$ emissions, but also affects other indicators such as "Fine particulate matter formation" and "Ionizing radiation". Fine particulate matter derives from the extraction and combustion of fossil fuels in power plants, whereas radionuclide releases, apart from the nuclear fuel cycle, appear on coal power plants, phosphate rock extraction, and even in oil and gas extraction as well [58]. As mentioned before, Greece's energy mix is dominated by oil, natural gas, and coal, especially lignite, a polluting and health harming form of coal [59] mined in open cast mines. As a result of the extraction and combustion of these energy sources, sulphur dioxide $\left(\mathrm{SO}_{2}\right)$, particulate matter $(\mathrm{PM})$, nitrogen oxides $\left(\mathrm{NO}_{\mathrm{x}}\right)$, heavy metals, and other pollutants are released into the atmosphere and subsequently affect human health and the environment [60]. Therefore, terrestrial acidification is also impacted, as terrestrial acidification may also occur from sulphur and nitrogen emissions into the air, as the $\mathrm{SO}_{2}, \mathrm{NO}_{2}$ alongside their reaction products may end up deposited into the soil or surface water and lead to changes in its chemical composition [61]. Furthermore, nitrogen oxides, together with phosphate contribute to freshwater and marine eutrophication [62]. The addition of $\mathrm{NO}_{\mathrm{x}}$ to the atmosphere possibly might enhance the formation of polar stratospheric clouds that activate chlorine-catalysed destruction of ozone and increase ozone in the troposphere [63]. Ground level ozone, or tropospheric ozone, is harmful for human health and is formed by the action of sunlight on ozone precursors, such as nitrogen oxides, VOCs methane and carbon monoxide [64-66], compounds that are related to the extraction and burning of fossil fuels $[67,68]$. Another category where a high impact is observed, is "Terrestrial ecotoxicity". Terrestrial ecotoxicity is mainly caused by emissions associated with nickel, chromium VI, and mercury [69]. Mercury, a toxic heavy metal, emerges as an impurity in fossil fuels, especially in coal, and in nonferrous metals [70], and as it is the case with nickel and chromium VI, both human carcinogens, it is released into the atmosphere when fossil fuels are burnt [71,72].

Apart from the toxicity of some heavy metals such as lead or mercury emitted from fossil fuel combustion [73], chemicals used in the production of ZIF-8 are also characterised as toxic and corrosive. According to the United Nation's Globally Harmonized System of Classification and Labelling of Chemicals, the linker of ZIF-8, 2-Methylimidazole is characterized as corrosive, irritant, and health hazardous while it is also suspected of causing cancer [74]. DMF is toxic and characterized as irritant and health hazardous while methanol is described as acute toxic, flammable, and health hazardous [75,76]. Both substances are volatile precursors to ground level ozone formation. Zinc nitrate hexahydrate is characterized as an oxidizer, irritant, and health hazardous, as it is acutely toxic and dangerous if swallowed [77]. Finally, Zinc is described as flammable and environmental hazardous that is highly toxic to aquatic life with enduring effects [78]. Consequently, these 
substances do contribute to the overall environmental impact of ZIF-8 synthesis. Section 3.1 explores the implications each process per synthetic route has on the environment.

\subsection{Environmental Analysis of Different Synthetic Routes}

Each synthetic route is investigated separately for the identification of their environmental hotspots during each synthesis stage. The synthetic procedures include processes such as stirring, centrifuge and drying in an oven as well as the use of materials such as zinc, zinc nitrate hexahydrate or tetrahydrate, de-ionized water, 2- methylimidazole, DMF, and methanol $(\mathrm{MeOH})$. The results are illustrated in Figures 4-8.

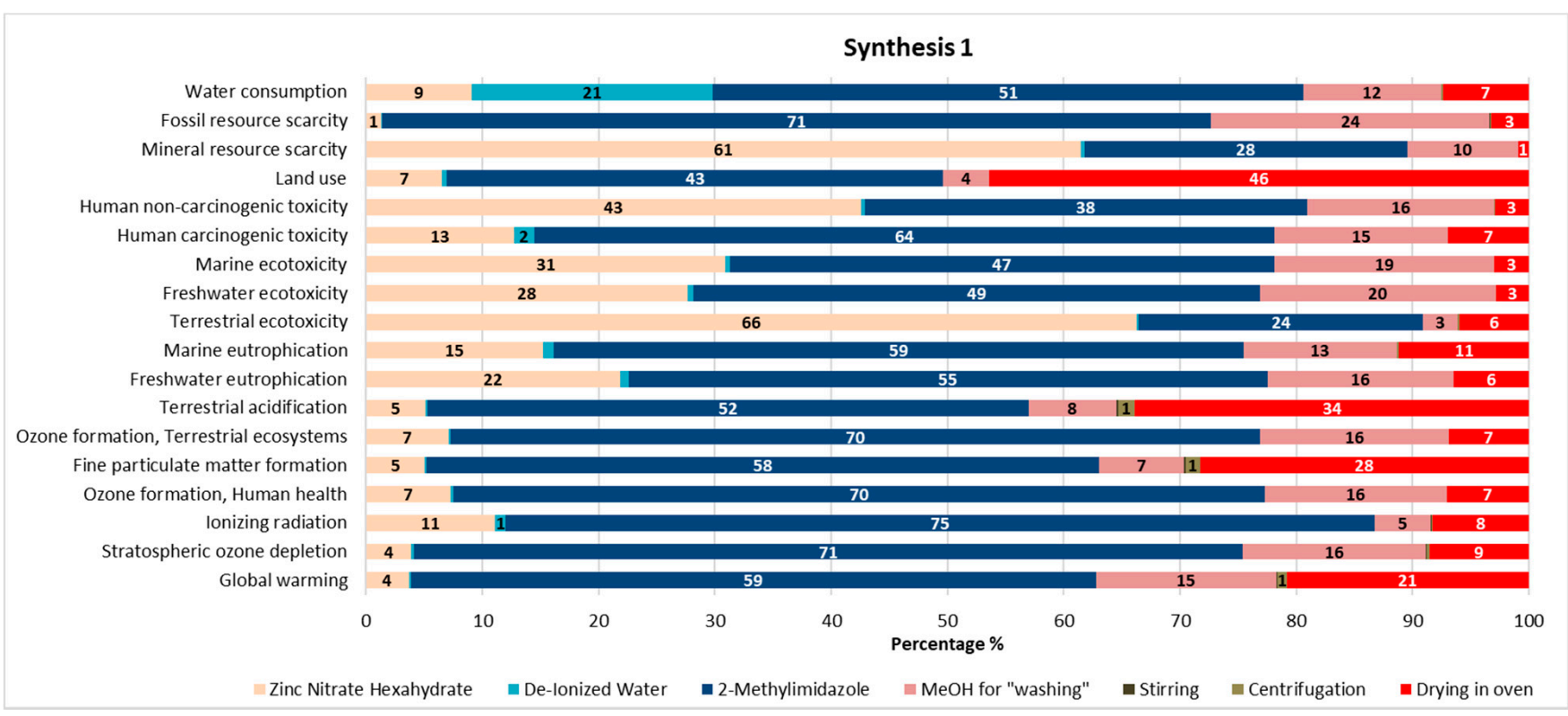

Figure 4. Life Cycle Assessment of the 1st synthetic approach of ZIF-8. Method: ReCiPe 2016, midpoint (H) V.1.01.

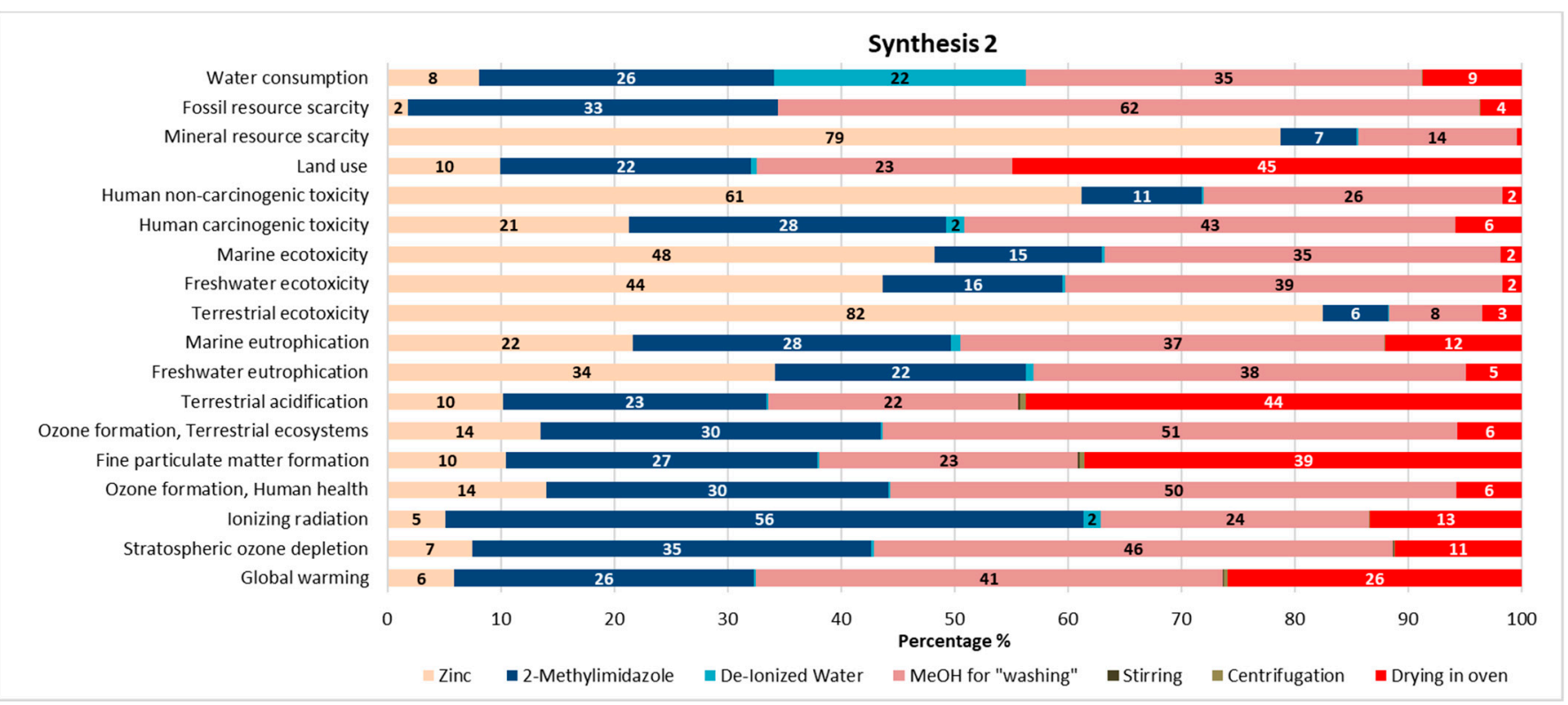

Figure 5. Life Cycle Assessment of the 2nd synthetic approach of ZIF-8. Method: ReCiPe 2016, midpoint (H) V.1.01. 


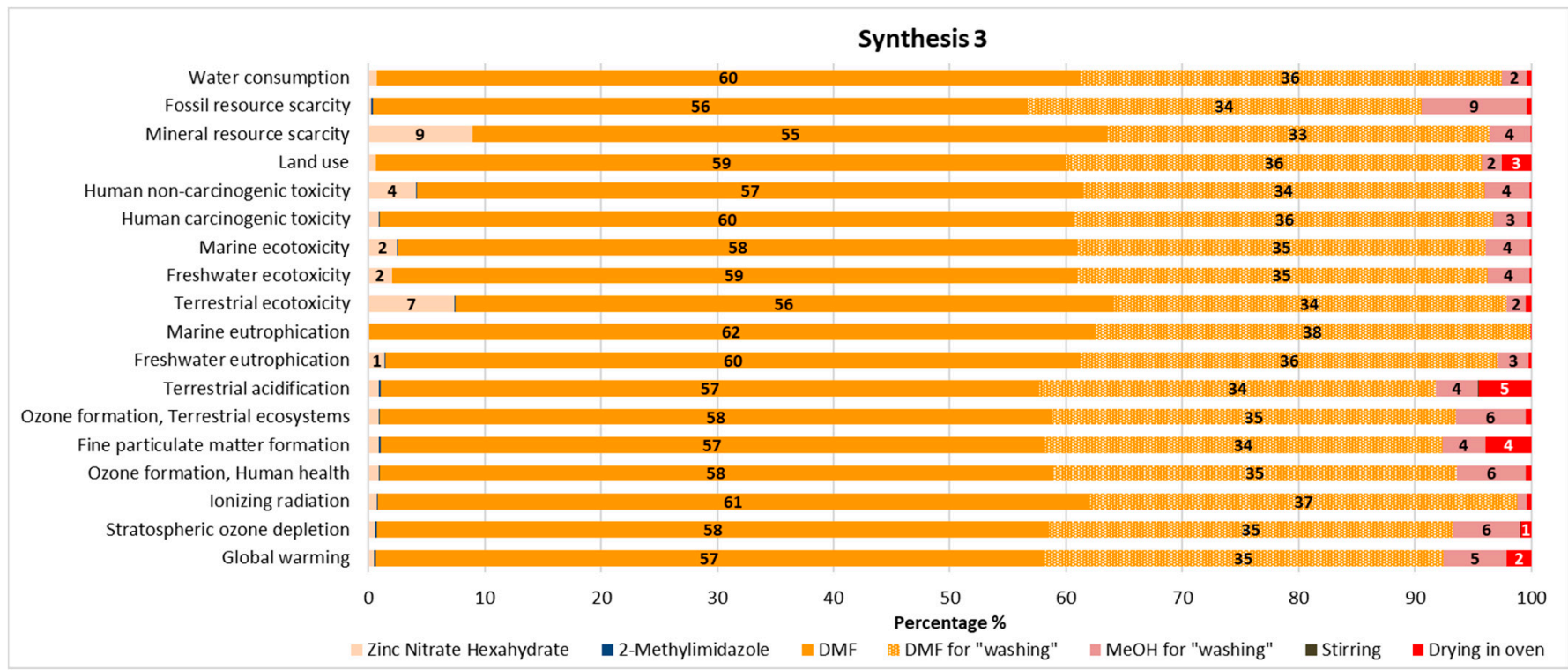

Figure 6. Life Cycle Assessment of the 3rd synthetic approach of ZIF-8. Method: ReCiPe 2016, midpoint (H) V.1.01.

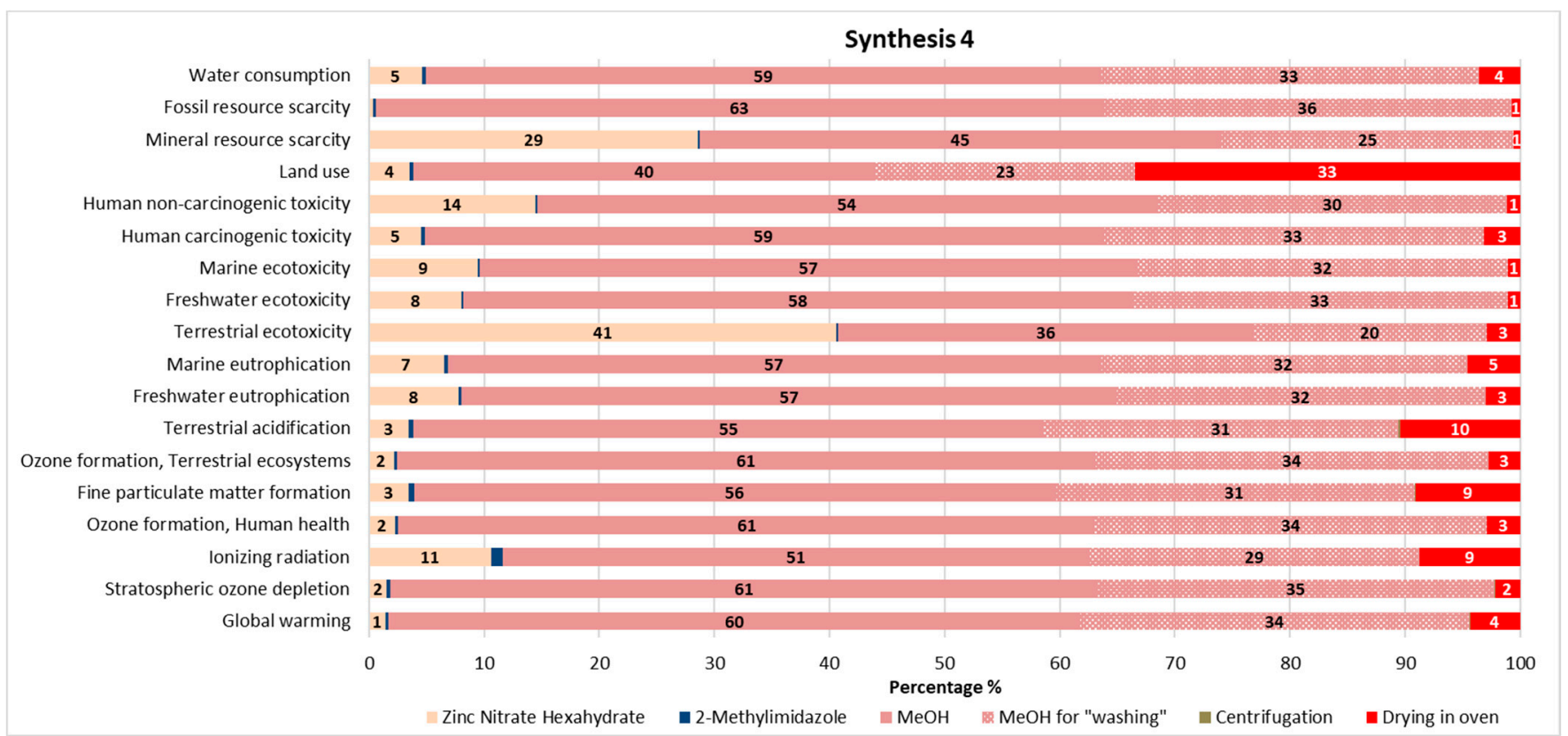

Figure 7. Life Cycle Assessment of the 4th synthetic approach of ZIF-8. Method: ReCiPe 2016, midpoint (H) V.1.01. 


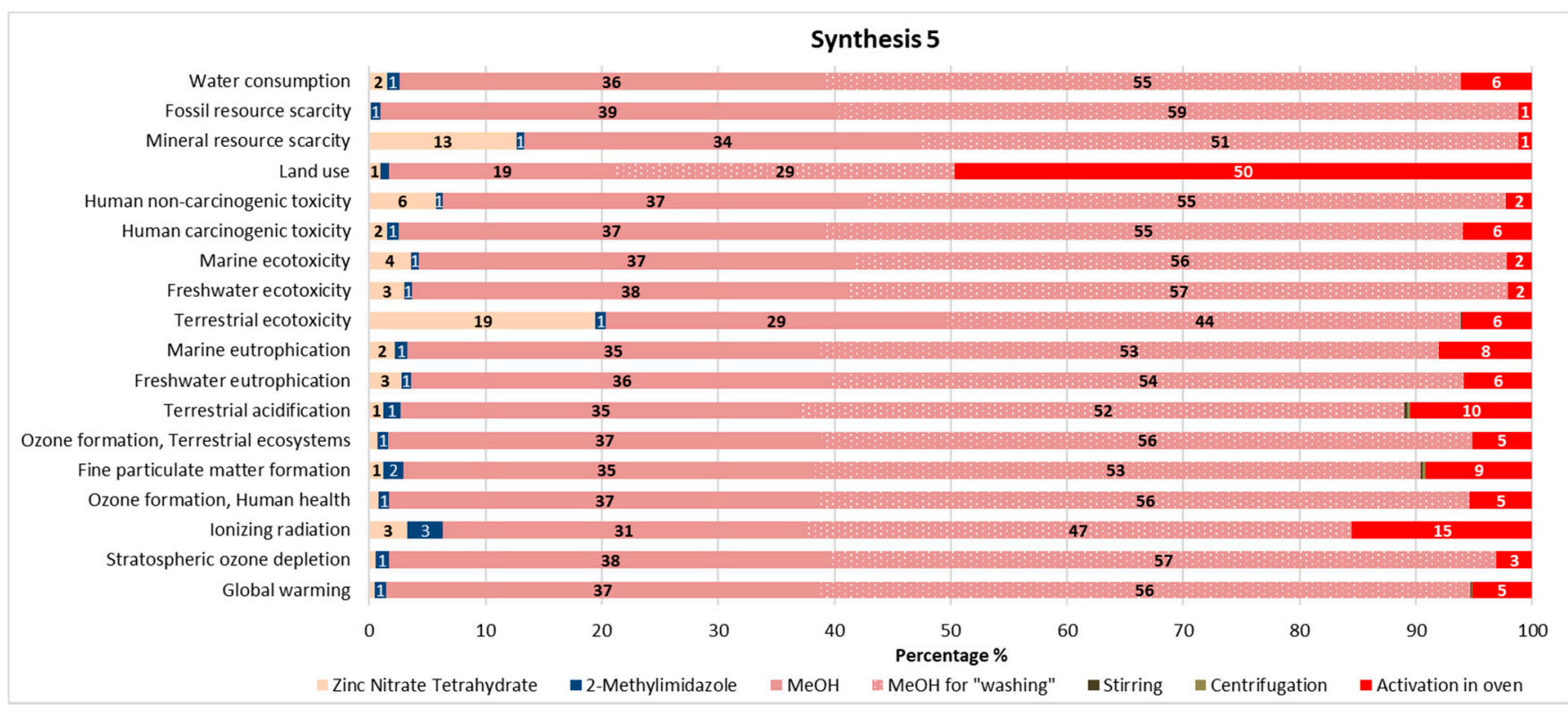

Figure 8. Life Cycle Assessment of the 5th synthetic approach of ZIF-8. Method: ReCiPe 2016, midpoint (H) V.1.01.

Overall, in Synthesis 1, 2-Methylimidazole, has a mean impact as an average of all 18 categories of $55 \%$ followed by zinc nitrate hexahydrate which has a mean impact of $19 \%$. Methanol used for washing the material after it is collected from the centrifugator, approximately has a mean impact of $13 \%$ while the energy consumed for drying the material in the oven has a mean impact of $12 \%$. De-ionized water has a mean environmental impact of $1.6 \%$ while the processes of centrifugation and stirring $0.3 \%$ and $0.03 \%$ respectively. In Synthesis 1, the linker, 2-Methylimidazole has the greatest impact in most categories. Further, 2-Methylimidazole's biggest impact is observed with regard to "Ionizing radiation" (75\%), "Stratospheric ozone depletion" (71\%), "Fossil fuel scarcity" (71\%) and the two"Ozone Formation" categories (70\% respectively) whereas its impact to the other categories cannot be neglected as the imidazolium based liquids are toxic and have a degrative behavior [79-81]. On the other hand, Zinc nitrate hexahydrate mainly impacts the categories "Terrestrial ecotoxicity" (66\%), "Mineral resource scarcity" (61\%), and "Human non-carcinogenic toxicity" (43\%), while it also affects marine and freshwater ecotoxicity categories ( $31 \%$ and $28 \%$ respectively). Zinc nitrate is considered to be highly toxic to aquatic life according to the European Chemicals Agency [82]. Methanol (MeOH) is used for cleaning, or "washing" the product after the latter is stirred and centrifugated and before entering the oven for drying. $\mathrm{MeOH}$ has a fair share of impact, $24 \%$ and $20 \%$, to "Fossil resource scarcity" and "Freshwater ecotoxicity" categories respectively. The process of drying the material in the oven mainly impacts the "Land use" category (46\%), as well as the "Terrestrial acidification" (34\%) and "Fine particulate matter formation" $(28 \%)$ categories. On the contrary, the processes of stirring and centrifugation have minor impacts, equal to or less than $1 \%$ in all impact categories. Interestingly, de-ionized water, which is the solvent used in Synthesis 1, has a 21\% impact on "Water consumption" and a minor $(<2 \%)$ impact on "Human carcinogenic toxicity" and "Marine eutrophication".

In the second synthetic route, methanol used for washing the material before the latter enters the oven, has the highest overall environmental mean impact among the processes and materials utilized to produce ZIF-8 (34\%). Its highest impact is observed with regard to "Fossil resource scarcity" (62\%), "Ozone formation, Terrestrial ecosystems" (51\%) and "Ozone formation, Human health" (50\%). The precursor of Synthesis 2, Zinc, contributes to $27 \%$ of the overall impacts. In particular, it has a $82 \%$ impact on "Terrestrial ecotoxicity", $79 \%$ on "Mineral resource scarcity", $61 \%$ on "Human non-carcinogenic toxicity", and $48 \%$ on "Marine ecotoxicity" is observed. The use of 2-methylimidazole is observed to contribute $24 \%$ to the overall environmental impacts as an average of all impact categories. 
The categories with the highest impacts due to the use of this linker are the "Ionizing radiation" (56\%), "Stratospheric ozone depletion" (35\%), and "Fossil resource scarcity", which account for $33 \%$. The process of drying the material in the oven has, on average, an impact of 13\%. In particular, it affects "Land use" (45\%), "Terrestrial acidification" (44\%), "Fine particulate matter formation" (39\%), and "Global warming" (26\%). The processes of stirring and centrifugation have minor impacts, less than $1 \%$, in the categories where they are observed, while their mean impact is $0.03 \%$ and $0.08 \%$, respectively. Finally, the main impact of the de-ionized water, the solvent of Synthesis 2, is observed with regard to "Water consumption" (22\%) while it contributes less than $2 \%$ to the overall impact on the environment as a mean value of all impact categories.

Overall, in Synthesis 3, DMF has the strongest mean impact as an average of all 18 categories of $93 \%, 58 \%$ as the synthesis solvent, and $35 \%$ as a cleaning agent. Methanol used for washing the material follows with a mean impact of $4 \%$. Zinc nitrate hexahydrate's overall mean contribution to the environmental impacts is slightly less than $2 \%$ while 2 Methylimidazole's mean impact is almost negligible $(0.08 \%)$. Finally, the processes of drying the material in the oven and stirring have a mean environmental impact of $1 \%$ and $0.005 \%$ respectively.

In particular, the reported amount of DMF used as a solvent has a higher impact than $54 \%$ on all 18 impact categories. If DMF's amount used as a solvent is to be added to that used for washing, then the impact to each category increases to more than $87 \%$. The highest observed impact of methanol is limited to 9\% ("Fossil resource scarcity"). The precursor of this synthesis, zinc nitrate hexahydrate, has a 9\% impact on "Mineral resource scarcity" and a 7\% impact on "Terrestrial ecotoxicity", whereas its impact on other categories is equal to or less than $4 \%$. The linker, 2-methylimidazole, has a negligible impact, less than $0.1 \%$, per category. As in the other syntheses, again, the energy consumed by the oven for the production of $1 \mathrm{~kg}$ ZIF-8 has an impact on "Land use" (3\%), "Terrestrial acidification" $(5 \%)$, "Fine particulate matter formation" ( $4 \%)$, and "Global warming" $(2 \%)$, whereas the energy consumed for stirring does not impose severe negative effects on the environment.

The third synthetic route is different from the first two approaches as, in this synthesis, DMF, a volatile compound, is used as the solvent as well as for partially washing the material. Many zeolitic imidazole framework- 8 crystalline structures presented in the literature are synthesized with organic solvents like DMF or methanol as in Synthesis 4. However, according to Kida et al., organic solvents are costly to obtain and might cause environmental implications as there is a risk imposed on the environment from toxicity. On the contrary, water is considered a better solvent to produce ZIF- 8 crystalline structures since it is easier to evacuate a ZIF-8 pore network from the molecules of water than the molecules of methanol or DMF and poses almost no risk to the environment [52]. This is clearly seen when comparing the impact of de-ionised water as a solvent in Synthesis 1 and 2 with the impact of DMF or methanol in Syntheses 3-5.

In Synthesis 4, methanol is utilized as the solvent of the solution that produces ZIF-8 as well as the cleaning agent. Methanol, traditionally produced from synthetic gas [83], is a volatile compound which is a precursor to ground level ozone formation that affects human health and terrestrial ecosystems. Furthermore, according to a 2004 study investigating the toxicity of methanol in aquatic ecosystems, it was found that, even at low concentration, this organic solvent can hinder the biological life cycle of fish and decrease primary productivity, water's alkalinity and phytoplankton's concentration [84]. Methanol also has impacts on "Land use" since, in general, any material that contains carbon (i.e., biomass or lignite) can be employed in methanol's production $[85,86]$ resulting in land transformation and land occupation. However, before methanol is produced, it requires a step known as gasification, a procedure for converting solid material fuel that contains carbon to combustible gas via partial oxidation, and this forms some undesirable pollutants, such as Nitrogen, Phosphorus, and Chlorine, that further impact freshwater eutrophication and ecotoxicity respectively [87]. As depicted in the results in Figure 7, methanol, as a solvent and as a cleaning agent, contributes $86 \%(55 \%$ as a solvent and $31 \%$ as a cleaning 
agent) to the overall environmental impacts as an average of all 18 impact categories. More specific, it has a great impact to "Fossil resource scarcity" (99\% cumulative), "Stratospheric ozone depletion" (96\% cumulative), "Ozone formation" (95\% cumulative for human health \& 95\% for terrestrial ecosystems), and "Global warming" (94\% cumulative). Following, zinc nitrate hexahydrate's average impact is $9 \%$, while its peak value is observed in the "Terrestrial ecotoxicity" category (41\%), whereas 2-Methylimidazole's mean impact is $0.3 \%$ and its highest observed value is seen for "Ionizing radiation" (1\%). The drying process of the material in the oven accounts for $5 \%$ and centrifugation for $0.02 \%$. Specifically, the energy consumption for drying the material in the oven accounts for a 33\% impact on "Land use".

In Synthesis 5, methanol used for washing the material after it is collected from the centrifugator has a mean impact of $52 \%$ while the amount of methanol used as a solvent has an average impact of $35 \%$. Zinc nitrate tetrahydrate's overall mean contribution to the environmental impacts is slightly more than $3 \%$ while 2-Methylimidazole's mean impact is smaller (1\%). On the contrary, the energy consumed for all processes (stirring, centrifugation, and activation) has a mean impact, as an average of all 18 categories, of $8 \%$.

In particular, methanol's cumulative impact, as a solvent and as a cleaning agent, on "Fossil resource scarcity" is 98\%, to "Stratospheric ozone depletion" 95\%, and to "Global warming" 93\%. As expected, due to methanol's volatile nature, a high impact is also observed with regard to ground level ozone formation, $93 \%$. With regard to the linker of the Synthesis, 2-Methylimidazole has a minor impact lower than $3 \%$ per category whereas the precursor of the synthesis, zinc nitrate tetrahydrate has a fair impact on "Mineral resource scarcity" and "Terrestrial ecotoxicity" (13\% and 19\% respectively). Considering the energy consumed for the production of $1 \mathrm{~kg}$ ZIF through the 5th synthetic route, we observe that the use of the oven to activate the material accounts for $50 \%$ of the impact on "Land use", $15 \%$ on "Ionizing radiation", and $10 \%$ of the impact on "Terrestrial acidification". Finally, it should be noted that, in Synthesis 5, larger amount of methanol is used for the production of $1 \mathrm{~kg}$ ZIF- 8 compared to the other syntheses, and as a result, the impact of methanol is higher than before.

Concluding, two hotspots are observed in the investigated synthetic procedures of ZIF-8. According to the results, the first hotspot concerns the use of organic solvents (DMF and methanol) in the synthetic procedure as it poses remarkable implications to several impact categories. On the contrary, the use of de-ionised water as a solvent in the synthetic procedure has minor implications on environmental sustainability. More particularly, with regard to the chemicals used as a solvent and as a cleaning agent for the production of ZIF-8 as it is the case in Synthesis 3-5, depending on the amount used on each synthesis, the use of methanol appeared to have an overall environmental impact that ranges from $86 \%$ (Synthesis 4) up to $87 \%$ (Synthesis 5), followed by $93 \%$ impact caused by the use of DMF and 97\% impact when DMF and methanol are combined (Synthesis 3). On the contrary, the overall implication to the environment of de-ionised water utilized solely as a solvent, as in the case in Syntheses 1 and 2, ranges from 1.5\% to 1.6\%, respectively. Interestingly, the overall impact of methanol which is used solely as a cleaning agent in Syntheses 1 and 2, is $13 \%$ and 34\%, respectively. The second hotspot is related to energy consumption, and especially the energy consumed for drying the material. This process, impacts most of the 18 midpoint level categories in all five synthetic routes (represented in Figures 4-8 and depicted with red color) while it has a greater impact on the first two synthetic routes. However, the impact energy has on the various synthetic routes is not as severe as that of the chemical solvents. The highest overall impact of energy as an average of all impact categories is $13 \%$ for Synthesis 2 followed by a $12 \%$ impact in Synthesis 1, while in the other three synthetic routes it is lower.

\subsection{Sensitivity Analysis-Effect of Diversifying the Energy Sources}

As seen from the detailed environmental assessment of each synthetic route in the previous section, energy is an impactful factor for the synthesis of $1 \mathrm{~kg}$ ZIF-8 that can be 
changed without affecting the general procedure of the synthetic route. Greece's energy mix for electricity production is mainly based on fossil fuels (IEA 2019: 50\% Oil, 21\% Natural gas, $15 \%$ Coal), and as a result, the impact on human health, ecosystems, and resources is not negligible. However, the environmental footprint of different energy sources may differentiate, and thus a more eco-friendly route for the synthesis of ZIF-8 might be of a great added value for the product. Therefore, a one-way sensitivity analysis was conducted taking into consideration different renewable energy sources for electricity production, namely solar power and wind power. In addition, the ever-increasing needs for clean energy originated from renewable sources and the potential of the later as enablers for a sustainable transition along with their steadily increasing incorporation to national grids indicates that renewable energy sources will gain an even higher share in energy production in the future [88]. In this work, the potential of a fully renewable energy dependent energy grid is exploited in order to explore how an energy invasive process like the production of ZIF-8 would be affected in the event renewable energy sources were dominant. The base scenario for the following sensitivity analysis is the 3rd synthetic route, which had the most severe impact on environmental sustainability based on the results illustrated in Figures 2 and 3, and it will be the reference for all comparisons with different energy sources, i.e., solar power and wind power. Table 3 shows the absolute contribution of each variation in energy sources while Figure 9 illustrates each process's percentage contribution in the midpoint impact categories for Synthesis 3, according to a hierarchic perspective.

Table 3. Life Cycle Assessment sensitivity analysis on Synthesis 3 involving different energy sources.

\begin{tabular}{|c|c|c|c|c|}
\hline Impact Category & Unit & $\begin{array}{c}\text { Synthesis 3_Greek } \\
\text { Conventional Energy Mix }\end{array}$ & $\begin{array}{l}\text { Synthesis } \\
\text { 3_Solar Power }\end{array}$ & $\begin{array}{l}\text { Synthesis } \\
\text { 3_Wind Power }\end{array}$ \\
\hline Global warming & $\mathrm{kg} \mathrm{CO} 2 \mathrm{eq}$ & 1571.16 & 1545.6 & 1543.98 \\
\hline Stratospheric ozone depletion & kg CFC11 eq & 0 & 0 & 0 \\
\hline Ionizing radiation & $\mathrm{kBq}$ Co-60 eq & 167.78 & 167.77 & 167.61 \\
\hline Ozone formation, Human health & $\mathrm{kg} \mathrm{NO}_{\mathrm{x}} \mathrm{eq}$ & 2.76 & 2.76 & 2.76 \\
\hline Fine particulate matter formation & $\mathrm{kg}$ PM2.5 eq & 2.21 & 2.14 & 2.13 \\
\hline Ozone formation, Terrestrial ecosystems & $\mathrm{kg} \mathrm{NO}_{\mathrm{x}} \mathrm{eq}$ & 2.9 & 2.9 & 2.9 \\
\hline Terrestrial acidification & $\mathrm{kg} \mathrm{SO}_{2} \mathrm{eq}$ & 5.88 & 5.65 & 5.64 \\
\hline Freshwater eutrophication & $\mathrm{kg} \mathrm{Peq}$ & 0.55 & 0.55 & 0.55 \\
\hline Marine eutrophication & kg N eq & 1.67 & 1.67 & 1.67 \\
\hline Terrestrial ecotoxicity & $\operatorname{kg~1,4-DCB}$ & 5798.03 & 5820.31 & 5782.1 \\
\hline Freshwater ecotoxicity & $\mathrm{kg} \mathrm{1,4-DCB}$ & 46.13 & 46.31 & 46.13 \\
\hline Marine ecotoxicity & $\mathrm{kg} \mathrm{1,4-DCB}$ & 64.58 & 64.82 & 64.57 \\
\hline Human carcinogenic toxicity & kg 1,4-DCB & 47.61 & 47.79 & 47.6 \\
\hline Human non-carcinogenic toxicity & $\mathrm{kg} \mathrm{1,4-DCB}$ & 1399.89 & 1403.08 & 1399.3 \\
\hline Land use & $\mathrm{m}^{2} \mathrm{a}$ crop eq & 29.95 & 30.5 & 29.96 \\
\hline Mineral resource scarcity & $\mathrm{kgCu} \mathrm{eq}$ & 5.12 & 5.14 & 5.24 \\
\hline Fossil resource scarcity & kg oil eq & 962.58 & 961.11 & 960.71 \\
\hline Water consumption & $\mathrm{m}^{3}$ & 23.81 & 23.82 & 24.31 \\
\hline
\end{tabular}

Overall, wind power utilized as the main energy source is found to have the smallest environmental footprint. In fact, except for "Marine eutrophication", "Mineral resource scarcity", and "Water consumption", the wind power-based scenario resulted in the lowest environmental impact with respect to the midpoint indicators as compared to the two other scenarios. For instance, it is found to decrease "Global warming", "Fine particulate matter formation", and "Terrestrial acidification" by 1.7\%, 3.4\%, and 4\%, respectively, as compared to the conventional energy mix. The utilisation of solar power for the energy mix of ZIF-8 is found as the second best among the three selected approaches with regard to its overall implications. Its main environmental impacts are attributed to midpoint indicators related to "Ionizing radiation", "Ozone formation", ecosystems such as the eutrophication- and toxicity-related categories and "Land use". The main observed reductions in environmental impacts due to the utilisation of solar power compared to the conventional energy mix 
are observed with regard to "Global warming" (1.6\%), "Fine particulate matter formation" $(3.2 \%)$, and "Terrestrial acidification" (3.8\%) (Figure 9).

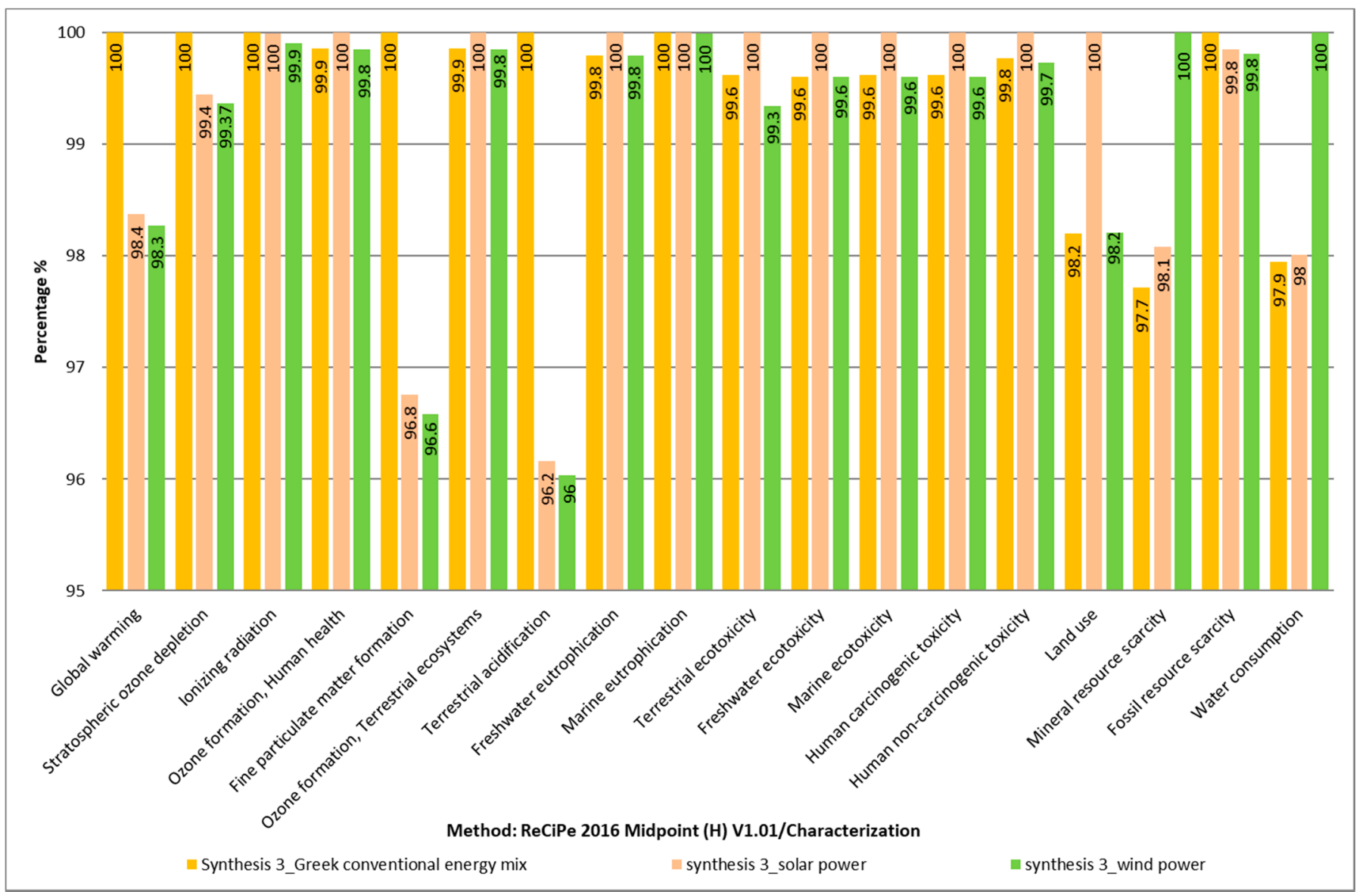

Figure 9. Comparison of Synthesis 3 impact to the environment based on various energy sources.

According to the damage assessment comparison (Figure 10), wind power poses less implications to the environment compared to the other two energy sources, i.e., solar power and Greece's conventional energy mix. If solely wind power is utilized to provide for the electricity needs of $1 \mathrm{~kg}$ ZIF- 8 synthesis, this corresponds to $2.1 \%$ less impact than the conventional energy mix with regard to human health, $1.7 \%$ with regard to ecosystems, and $0.2 \%$ with regard to resources. Solar power, also shows reduced impact to human health $(2 \%)$, ecosystems $(1.6 \%)$ and resources $(0.2 \%)$ in comparison to the Greek energy mix. Overall, the utilization of eco-friendly energy sources, especially wind power, is a feasible alternative capable to enhance the environmental sustainability of ZIF-8 synthesis and enable the eco-friendly integration of ZIF-8 into the innovative technologies that address emerging environment challenges. 


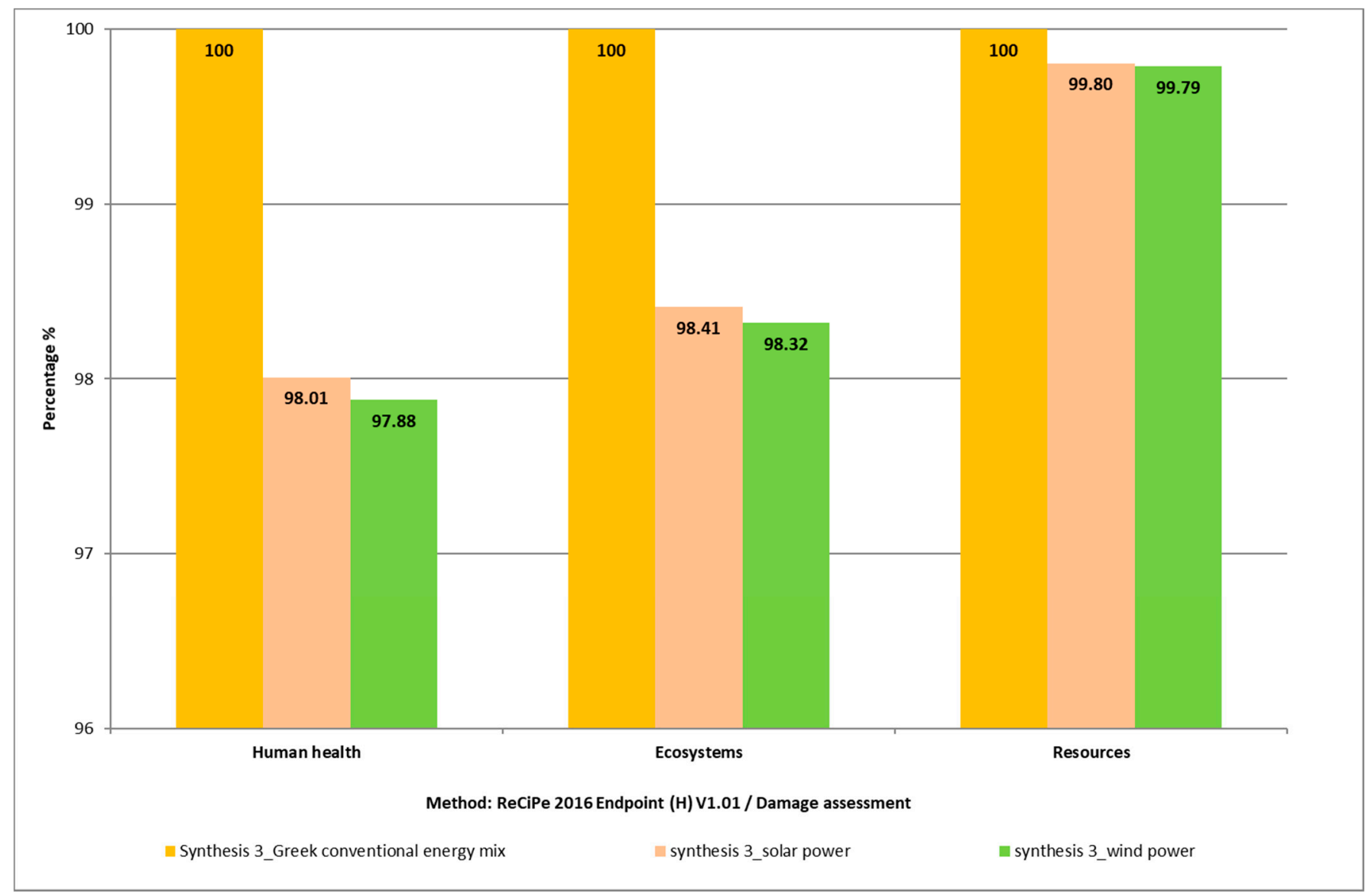

Figure 10. Comparative damage assessment of various energy sources in ZIF-8 3rd production process.

\section{Conclusions}

Only a limited amount of research has been conducted with the LCA approach in the nanomaterials sector in order to assess their environmental impact and identify possible hotspots for the future sustainable optimization of the synthesis procedure. In this work, five different synthesis routes to produce ZIF-8 porous nanomaterials were examined and assessed under an LCA approach. It was found that de-ionised water utilized as a solvent is more favorable to the environment than DMF or methanol as it was observed in the analysis of the five different synthetic routes. However, the energy required for the synthetic procedure plays also a role on the overall environmental sustainability. As revealed from the results, the environmental hotspots of the synthetic routes were the energy usage (accounting up to $13 \%$ of the mean environmental impacts) as well as the solvents used. In particular, methanol accounts for at least $35 \%$ of the mean environmental impact when it is utilized solely as a solvent whereas DMF to $58 \%$. On the contrary, the use of deionized water as a solvent decreases the mean environmental impact of the solvent significantly, to less than $2 \%$, with the highest implications observed with regard to water consumption $(\sim 20 \%)$. Moreover, utilizing organic solvents as cleaning agents further increases their impact to the environment. Findings also revealed that a synthetic route that utilized DMF as a solvent, but consumed less energy than other synthetic routes, had a higher impact in categories related to energy consumption emissions, such as global warming, stratospheric ozone depletion, terrestrial acidification, or fine particulate matter formation. Moreover, it had higher impacts to ecosystems compared to methanol, despite the amount of DMF being utilized was less than that of methanol's.

In line with other research conducted, this work concludes to the contribution of the energy consumption in the environmental impacts of the different synthetic routes. Nonetheless the impacts depend on the energy source and are therefore highly dependable 
on the country the synthesis of the nanomaterials will take place. Cleaner electricity sources provide cleaner nanomaterials production. In particular, the same synthesis procedure of a nanomaterial will have $2 \%$ less overall impact on human health if the energy source derives from solar, $2.1 \%$ from wind; $1.6 \%$ less overall impact on ecosystems if the energy source derives from solar, and $1.7 \%$ from wind, whereas as it was found that solar and wind power would be slightly less harmful $(0.2 \%)$ to resources compared to conventional energy mix.

The outcomes of this work suggest that utilizing ZIF-8 for carbon capture applications or for other alternative climate change mitigation strategies should be coupled with "green" production processes including clean energy sources, as well as the implementation of a life cycle assessment analysis. As seen from the results, the production of ZIF-8 carbon capture material comes with an environmental cost, which although in this work is based on lab scale calculations and it might not be representative of industrial scale processes, it is indicative that ZIF-8 should be carefully evaluated on its synthetic procedure before being utilized for carbon capture applications. Otherwise, the goal to counterbalance the impacts of climate change might not be achieved.

Nonetheless this research work also identified several obstacles in the application of environmental assessments in the nanotechnology sector. Initially the lack of Life Cycle Inventories for the synthesis procedure since there is limited available information of the detailed synthetic procedure in research publications. Lastly, there is a lack of scientific work in relation to the recycling paths and processes that could take place in the nanotechnology sector, and this would alter significantly the environmental impacts of each material. In particular, recycling ZIF-8 would increase its overall environmental sustainability as there would be reductions in the amount of hazardous chemicals and in the energy consumed for its production. In fact, composite ZIF-8 materials resulted from encapsulating processes are reported as reusable $[89,90]$. In addition, circular approaches to the synthesis of ZIF8 resulting from recycled mother liquors have also been reported [39,51,91,92]. Therefore, although research on ZIF-8 recyclability is scarce, its promising potential applications should stimulate future studies to exploit reusable ZIF-8 components, contributing to the overall circularity of the material.

Further recommendations are suggested for the synthesis optimization, with the replacement of chemicals for the cleaning and purification of nanomaterials with water, as well as other means of purification. Future work should explore the life cycle assessment of various other synthetic routes of ZIF-8, as well as other porous nanomaterials, in order to provide a reference base that will enable the evaluation of their environmental sustainability and their effective integration into applications in various industrial sectors, such as transportation, energy, or the built environment.

Author Contributions: Conceptualization, V.N. and D.P.; methodology, V.N. and D.P.; software, V.N.; validation, V.N. and D.P.; formal analysis, V.N., I.K. and D.P.; investigation, V.N., D.P. and I.K.; writing-original draft preparation, V.N. with support from D.P. and I.K.; review and editing, D.P., M.N.A. and A.L.P.; supervision, M.N.A., A.L.P. and D.P. All authors have read and agreed to the published version of the manuscript.

Funding: This research has received funding from the European Union's Horizon 2020 research and innovation programme under the Marie Skłodowska-Curie Grant Agreement No 765057SAFERUP! Project.

Acknowledgments: The authors would like to acknowledge the European Union's Horizon 2020 research and innovation programme under the Marie Skłodowska-Curie Grant Agreement No 765057, SAFERUP!, website https: / / site.unibo.it/saferup/en (accessed on 9 June 2021).

Conflicts of Interest: The authors declare no conflict of interest.

\section{References}

1. Arnall, A.; Parr, D. Moving the Nanoscience and Technology (NST) Debate Forwards: Short-Term Impacts, Long-Term Uncertainty and the Social Constitution. Technol. Soc. 2005, 27, 23-38. [CrossRef] 
2. Kousis, I.; Pisello, A.L. For the Mitigation of Urban Heat Island and Urban Noise Island: Two Simultaneous Sides of Urban Discomfort. Environ. Res. Lett. 2020, 15, 103004. [CrossRef]

3. Wang, H.; Zhu, Q.-L.; Zou, R.; Xu, Q. Metal-Organic Frameworks for Energy Applications. Chem 2017, 2, 52-80. [CrossRef]

4. Qiu, T.; Liang, Z.; Guo, W.; Tabassum, H.; Gao, S.; Zou, R. Metal-Organic Framework-Based Materials for Energy Conversion and Storage. ACS Energy Lett. 2020, 5, 520-532. [CrossRef]

5. Li, H.; Wang, K.; Sun, Y.; Lollar, C.T.; Li, J.; Zhou, H.-C. Recent Advances in Gas Storage and Separation Using Metal-Organic Frameworks. Mater. Today 2018, 21, 108-121. [CrossRef]

6. Aniruddha, R.; Sreedhar, I.; Reddy, B.M. MOFs in Carbon Capture-Past, Present and Future. J. CO2 Util. $2020,42,101297$. [CrossRef]

7. $\mathrm{Hu}, \mathrm{Z}$; Wang, Y.; Shah, B.B.; Zhao, D. $\mathrm{CO}_{2}$ Capture in Metal-Organic Framework Adsorbents: An Engineering Perspective. Adv. Sustain. Syst. 2019, 3, 1800080. [CrossRef]

8. Cohen, S.M. Modifying MOFs: New Chemistry, New Materials. Chem. Sci. 2010, 1, 32-36. [CrossRef]

9. Mertzenich, C.L.; Papaefstathiou, G.S.; Friščić, T.; Hamilton, T.D.; Bučar, D.-K.; Swenson, D.C.; MacGillivray, L.R. Inverted metal-organic frameworks: Isoreticular decoration with organic anions using principles of supramolecular chemistry. J. Coord. Chem. 2021, 74, 169-177. [CrossRef]

10. Kitagawa, S.; Kitaura, R.; Noro, S. Functional Porous Coordination Polymers. Angew. Chem. Int. Ed. 2004, 43, $2334-2375$. [CrossRef] [PubMed]

11. Papadaki, D.; Kiriakidis, G.; Tsoutsos, T. Chapter 11-Applications of Nanotechnology in Construction Industry. In Fundamentals of Nanoparticles: Classifications, Synthesis Methods, Properties and Characterization; Barhoum, A., Hamdy Makhlouf, A.S., Eds.; Micro and Nano Technologies; Elsevier: Amsterdam, The Netherlands, 2018; pp. 343-370. [CrossRef]

12. Shafique, M.; Luo, X. Nanotechnology in Transportation Vehicles: An Overview of Its Applications, Environmental, Health and Safety Concerns. Materials 2019, 12, 2493. [CrossRef] [PubMed]

13. Singh, T.; Shukla, S.; Kumar, P.; Wahla, V.; Bajpai, V.K.; Rather, I.A. Application of Nanotechnology in Food Science: Perception and Overview. Front. Microbiol. 2017, 8. [CrossRef] [PubMed]

14. Xu, X.; Wang, H.; Liu, J.; Yan, H. The Applications of Zeolitic Imidazolate Framework-8 in Electrical Energy Storage Devices: A Review. J. Mater. Sci. Mater. Electron. 2017, 28, 7532-7543. [CrossRef]

15. Burtch, N.C.; Jasuja, H.; Walton, K.S. Water Stability and Adsorption in Metal-Organic Frameworks. Chem. Rev. 2014, 114, 10575-10612. [CrossRef]

16. Xie, L.-H.; Xu, M.-M.; Liu, X.-M.; Zhao, M.-J.; Li, J.-R. Hydrophobic Metal-Organic Frameworks: Assessment, Construction, and Diverse Applications. Adv. Sci. 2020, 7, 1901758. [CrossRef]

17. Sann, E.E.; Pan, Y.; Gao, Z.; Zhan, S.; Xia, F. Highly Hydrophobic ZIF-8 Particles and Application for Oil-Water Separation. Sep. Purif. Technol. 2018, 206, 186-191. [CrossRef]

18. Park, K.S.; Ni, Z.; Côté, A.P.; Choi, J.Y.; Huang, R.; Uribe-Romo, F.J.; Chae, H.K.; O’Keeffe, M.; Yaghi, O.M. Exceptional Chemical and Thermal Stability of Zeolitic Imidazolate Frameworks. Proc. Natl. Acad. Sci. USA 2006, 103, 10186-10191. [CrossRef]

19. Phan, A.; Doonan, C.J.; Uribe-Romo, F.J.; Knobler, C.B.; O’Keeffe, M.; Yaghi, O.M. Synthesis, Structure, and Carbon Dioxide Capture Properties of Zeolitic Imidazolate Frameworks. Acc. Chem. Res. 2010, 43, 58-67. [CrossRef]

20. Banerjee, R.; Phan, A.; Wang, B.; Knobler, C.; Furukawa, H.; O’Keeffe, M.; Yaghi, O.M. High-Throughput Synthesis of Zeolitic Imidazolate Frameworks and Application to $\mathrm{CO}_{2}$ Capture. Science 2008, 319, 939-943. [CrossRef]

21. Chen, B.; Yang, Z.; Zhu, Y.; Xia, Y. Zeolitic Imidazolate Framework Materials: Recent Progress in Synthesis and Applications. J. Mater. Chem. A 2014, 2, 16811-16831. [CrossRef]

22. Hwang, S.; Chi, W.S.; Lee, S.J.; Im, S.H.; Kim, J.H.; Kim, J. Hollow ZIF-8 Nanoparticles Improve the Permeability of Mixed Matrix Membranes for $\mathrm{CO}_{2} / \mathrm{CH}_{4}$ Gas Separation. J. Membr. Sci. 2015, 480, 11-19. [CrossRef]

23. Castro-Muñoz, R.; Fíla, V. Effect of the ZIF-8 Distribution in Mixed-Matrix Membranes Based on Matrimid ${ }^{\circledR} 5218-\mathrm{PEG}$ on CO 2 Separation. Chem. Eng. Technol. 2019, 42, 744-752. [CrossRef]

24. Cousin Saint Remi, J.; Rémy, T.; Van Hunskerken, V.; van de Perre, S.; Duerinck, T.; Maes, M.; De Vos, D.; Gobechiya, E.; Kirschhock, C.E.A.; Baron, G.V.; et al. Biobutanol Separation with the Metal-Organic Framework ZIF-8. ChemSusChem 2011, 4, 1074-1077. [CrossRef]

25. Xue, W.; Zhou, Q.; Li, F.; Ondon, B.S. Zeolitic Imidazolate Framework-8 (ZIF-8) as Robust Catalyst for Oxygen Reduction Reaction in Microbial Fuel Cells. J. Power Sources 2019, 423, 9-17. [CrossRef]

26. Zhu, M.; Srinivas, D.; Bhogeswararao, S.; Ratnasamy, P.; Carreon, M.A. Catalytic Activity of ZIF-8 in the Synthesis of Styrene Carbonate from $\mathrm{CO}_{2}$ and Styrene Oxide. Catal. Commun. 2013, 32, 36-40. [CrossRef]

27. Olaniyan, B.; Saha, B. Comparison of Catalytic Activity of ZIF-8 and Zr/ZIF-8 for Greener Synthesis of Chloromethyl Ethylene Carbonate by $\mathrm{CO}_{2}$ Utilization. Energies 2020, 13, 521. [CrossRef]

28. Cardoso, J.C.; Stulp, S.; de Brito, J.F.; Flor, J.B.S.; Frem, R.C.G.; Zanoni, M.V.B. MOFs Based on ZIF-8 Deposited on TiO 2 Nanotubes Increase the Surface Adsorption of $\mathrm{CO}_{2}$ and Its Photoelectrocatalytic Reduction to Alcohols in Aqueous Media. Appl. Catal. B Environ. 2018, 225, 563-573. [CrossRef]

29. Huang, Z.; Dong, P.; Zhang, Y.; Nie, X.; Wang, X.; Zhang, X. A ZIF-8 Decorated $\mathrm{TiO}_{2}$ Grid-like Film with High $\mathrm{CO}_{2}$ Adsorption for $\mathrm{CO}_{2}$ Photoreduction. J. CO2 Util. 2018, 24, 369-375. [CrossRef] 
30. Chang, C.-W.; Kao, Y.-H.; Shen, P.-H.; Kang, P.-C.; Wang, C.-Y. Nanoconfinement of Metal Oxide MgO and ZnO in Zeolitic Imidazolate Framework ZIF-8 for $\mathrm{CO}_{2}$ Adsorption and Regeneration. J. Hazard. Mater. 2020, 400, 122974. [CrossRef]

31. Khan, I.U.; Othman, M.H.D.; Jilani, A.; Ismail, A.F.; Hashim, H.; Jaafar, J.; Rahman, M.A.; Rehman, G.U. Economical, Environmental Friendly Synthesis, Characterization for the Production of Zeolitic Imidazolate Framework-8 (ZIF-8) Nanoparticles with Enhanced $\mathrm{CO}_{2}$ Adsorption. Arab. J. Chem. 2018, 11, 1072-1083. [CrossRef]

32. Yang, S.; Lu, S.; Cheng, Y.; Lu, Z.; Liu, X.; Qin, Y.; Zhao, R.; Zheng, L.; Cao, Q. HDBB@ZIF-8 Fluorescent Nanoprobe with Hereditary Alcohols Selectivity for Chemical Sensing. Microporous Mesoporous Mater. 2020, 294, 109959. [CrossRef]

33. Zhan, M.; Hussain, S.; AlGarni, T.S.; Shah, S.; Liu, J.; Zhang, X.; Ahmad, A.; Javed, M.S.; Qiao, G.; Liu, G. Facet Controlled Polyhedral ZIF-8 MOF Nanostructures for Excellent $\mathrm{NO}_{2}$ Gas-Sensing Applications. Mater. Res. Bull. 2021, 136, 111133. [CrossRef]

34. Matatagui, D.; Sainz-Vidal, A.; Gràcia, I.; Figueras, E.; Cané, C.; Saniger, J. Improving Sensitivity of a Chemoresistive Hydrogen Sensor by Combining ZIF-8 and ZIF-67 Nanocrystals. Proceedings 2017, 1, 462. [CrossRef]

35. Lin, X.; Gao, G.; Zheng, L.; Chi, Y.; Chen, G. Encapsulation of Strongly Fluorescent Carbon Quantum Dots in Metal-Organic Frameworks for Enhancing Chemical Sensing. Anal. Chem. 2014, 86, 1223-1228. [CrossRef] [PubMed]

36. Sun, C.-Y.; Qin, C.; Wang, X.-L.; Yang, G.-S.; Shao, K.-Z.; Lan, Y.-Q.; Su, Z.-M.; Huang, P.; Wang, C.-G.; Wang, E.-B. Zeolitic Imidazolate Framework-8 as Efficient PH-Sensitive Drug Delivery Vehicle. Dalton Trans. 2012, 41, 6906-6909. [CrossRef] [PubMed]

37. Vasconcelos, I.B.; da Silva, T.G.; Militão, G.C.G.; Soares, T.A.; Rodrigues, N.M.; Rodrigues, M.O.; da Costa, N.B.; Freire, R.O.; Junior, S.A. Cytotoxicity and Slow Release of the Anti-Cancer Drug Doxorubicin from ZIF-8. RSC Adv. 2012, 2, 9437-9442. [CrossRef]

38. He, L.; Wang, T.; An, J.; Li, X.; Zhang, L.; Li, L.; Li, G.; Wu, X.; Su, Z.; Wang, C. Carbon Nanodots@zeolitic Imidazolate Framework-8 Nanoparticles for Simultaneous PH-Responsive Drug Delivery and Fluorescence Imaging. CrystEngComm 2014, 16, 3259-3263. [CrossRef]

39. García Palacín, M.; Martínez, J.I.; Paseta, L.; Deacon, A.; Johnson, T.; Malankowska, M.; Téllez, C.; Coronas, J. Sized-Controlled ZIF-8 Nanoparticle Synthesis from Recycled Mother Liquors: Environmental Impact Assessment. ACS Sustain. Chem. Eng. 2020, 8, 2973-2980. [CrossRef]

40. Luo, H.; Cheng, F.; Huelsenbeck, L.; Smith, N. Comparison between Conventional Solvothermal and Aqueous Solution-Based Production of UiO-66-NH2: Life Cycle Assessment, Techno-Economic Assessment, and Implications for $\mathrm{CO}_{2}$ Capture and Storage. J. Environ. Chem. Eng. 2021, 9, 105159. [CrossRef]

41. Grande, C.A.; Blom, R.; Spjelkavik, A.; Moreau, V.; Payet, J. Life-Cycle Assessment as a Tool for Eco-Design of Metal-Organic Frameworks (MOFs). Sustain. Mater. Technol. 2017, 14, 11-18. [CrossRef]

42. Feijoo, S.; González-García, S.; Moldes-Diz, Y.; Vazquez-Vazquez, C.; Feijoo, G.; Moreira, M.T. Comparative Life Cycle Assessment of Different Synthesis Routes of Magnetic Nanoparticles. J. Clean. Prod. 2017, 143, 528-538. [CrossRef]

43. Sendão, R.; del Valle Martínez deYuso, M.; Algarra, M.; Esteves da Silva, J.C.G.; Pinto da Silva, L. Comparative Life Cycle Assessment of Bottom-up Synthesis Routes for Carbon Dots Derived from Citric Acid and Urea. J. Clean. Prod. 2020, 254, 120080. [CrossRef]

44. Papadaki, D.; Foteinis, S.; Mhlongo, G.H.; Nkosi, S.S.; Motaung, D.E.; Ray, S.S.; Tsoutsos, T.; Kiriakidis, G. Life Cycle Assessment of Facile Microwave-Assisted Zinc Oxide (ZnO) Nanostructures. Sci. Total Environ. 2017, 586, 566-575. [CrossRef]

45. James, F.; Consoli, F.; Denison, R.; Dickson, K.; Mohin, T.; Vigon, B. A Conceptual Framework for Life-Cycle Impact Assessment; Society of Environmental Toxicology and Chemistry and SETAC Foundation for Environmental Education, Inc.: Pensacola, FL, USA, 1993; Available online: https:/ / cdn.ymaws.com/www.setac.org/resource/resmgr/books/lca_archive/impact_assessment.pdf (accessed on 1 June 2021).

46. Kousis, I.; Fabiani, C.; Ercolanoni, L.; Pisello, A.L. Using Bio-Oils for Improving Environmental Performance of an Advanced Resinous Binder for Pavement Applications with Heat and Noise Island Mitigation Potential. Sustain. Energy Technol. Assess. 2020, 39, 100706. [CrossRef]

47. Finkbeiner, M. The International Standards as the Constitution of Life Cycle Assessment: The ISO 14040 Series and Its Offspring. In Background and Future Prospects in Life Cycle Assessment; Klöpffer, W., Ed.; LCA Compendium-The Complete World of Life Cycle Assessment; Springer: Dordrecht, The Netherlands, 2014; pp. 85-106. [CrossRef]

48. ReCiPe 2016: A Harmonized Life Cycle Impact Assessment Method at Midpoint and Endpoint Level Report I: Characterization 2016-0104. Available online: https:/ / www.rivm.nl/bibliotheek/rapporten/2016-0104.html (accessed on 26 May 2021 ).

49. Frischknecht, R.; Jungbluth, N.; Althaus, H.-J.; Doka, G.; Dones, R.; Heck, T.; Hellweg, S.; Hischier, R.; Nemecek, T.; Rebitzer, G.; et al. The Ecoinvent Database: Overview and Methodological Framework (7 Pp). Int. J. Life Cycle Assess. 2005, 10, 3-9. [CrossRef]

50. Papadaki, D.; Foteinis, S.; Binas, V.; Assimakopoulos, M.N.; Tsoutsos, T.; Kiriakidis, G. A Life Cycle Assessment of PCM and VIP in Warm Mediterranean Climates and Their Introduction as a Strategy to Promote Energy Savings and Mitigate Carbon Emissions. AIMS Mater. Sci. 2019, 6, 944-959. [CrossRef]

51. Şahin, F.; Topuz, B.; Kalıpçılar, H. Synthesis of ZIF-7, ZIF-8, ZIF-67 and ZIF-L from Recycled Mother Liquors. Microporous Mesoporous Mater. 2018, 261, 259-267. [CrossRef]

52. Kida, K.; Okita, M.; Fujita, K.; Tanaka, S.; Miyake, Y. Formation of High Crystalline ZIF-8 in an Aqueous Solution. CrystEngComm 2013, 15, 1794-1801. [CrossRef]

53. Lee, Y.-R.; Jang, M.-S.; Cho, H.-Y.; Kwon, H.-J.; Kim, S.; Ahn, W.-S. ZIF-8: A Comparison of Synthesis Methods. Chem. Eng. J. 2015, 271, 276-280. [CrossRef] 
54. Tsai, C.-W.; Niemantsverdriet, J.W.; Langner, E.H.G. Enhanced $\mathrm{CO}_{2}$ Adsorption in Nano-ZIF-8 Modified by Solvent Assisted Ligand Exchange. Microporous Mesoporous Mater. 2018, 262, 98-105. [CrossRef]

55. Greece-Countries \& Regions-IEA. Available online: https://www.iea.org/countries/greece (accessed on 9 June 2021).

56. Li, Q.-Q.; Liu, H.; Zheng, T.-T.; Liu, P.; Song, J.-X.; Wang, Y.-Y. The Effect of Coordinated Solvent Molecules on Metal Coordination Environments in Single-Crystal-to-Single-Crystal Transformations. CrystEngComm 2020, 22, 6750-6775. [CrossRef]

57. Seetharaj, R.; Vandana, P.V.; Arya, P.; Mathew, S. Dependence of Solvents, PH, Molar Ratio and Temperature in Tuning Metal Organic Framework Architecture. Arab. J. Chem. 2019, 12, 295-315. [CrossRef]

58. Frischknecht, R.; Braunschweig, A.; Hofstetter, P.; Suter, P. Human health damages due to ionising radiation in life cycle impact assessment. Environ. Impact Assess. Rev. 2000, 20, 159-189. [CrossRef]

59. HEAL. Lignite Coal-Health Effects and Recommendations from the Health Sector. 2018. Available online: https://www.envhealth.org/wp-content/uploads/2018/12/HEAL-Lignite-Briefing-en_web.pdf (accessed on 3 June 2021).

60. Perera, F. Pollution from Fossil-Fuel Combustion Is the Leading Environmental Threat to Global Pediatric Health and Equity: Solutions Exist. Int. J. Environ. Res. Public. Health 2018, 15, 16. [CrossRef]

61. European Environment Agency. Europe's Environment-The Dobris Assessment. Chapter 31. Acidification-1995. Available online: https: / / www.eea.europa.eu/publications/92-826-5409-5/page031new.html (accessed on 2 June 2021).

62. Ngatia, L.; Grace, J.M., III; Moriasi, D.; Taylor, R. Nitrogen and Phosphorus Eutrophication. In Marine Ecosystems, Monitoring of Marine Pollution; Fouzia, B.H., Ed.; IntechOpen: London, UK, 2019; Available online: https://www.intechopen.com/chapters/64 674 (accessed on 1 June 2021). [CrossRef]

63. European Environment Agency. Europe's Environment-The Dobris Assessment. Chapter 28. Stratospheric Ozone Depletion. 1995. Available online: https:/ / www.eea.europa.eu/publications/92-826-5409-5/chap28.zip/view (accessed on 2 June 2021).

64. Berezina, E.; Moiseenko, K.; Skorokhod, A.; Pankratova, N.V.; Belikov, I.; Belousov, V.; Elansky, N.F. Impact of VOCs and NOx on Ozone Formation in Moscow. Atmosphere 2020, 11, 1262. [CrossRef]

65. Carrillo-Torres, E.R.; Hernández-Paniagua, I.Y.; Mendoza, A. Use of Combined Observational- and Model-Derived Photochemical Indicators to Assess the $\mathrm{O}_{3}$-NOx-VOC System Sensitivity in Urban Areas. Atmosphere 2017, 8, 22. [CrossRef]

66. Skowera, B.; Zuśka, Z.; Baranowska, A. Temporal Variability of Tropospheric Ozone Pollution in the Agricultural Region of Central-Eastern Poland. Sustainability 2020, 12, 7633. [CrossRef]

67. Hmiel, B.; Petrenko, V.V.; Dyonisius, M.N.; Buizert, C.; Smith, A.M.; Place, P.F.; Harth, C.; Beaudette, R.; Hua, Q.; Yang, B.; et al. Preindustrial 14 CH 4 Indicates Greater Anthropogenic Fossil CH 4 Emissions. Nature 2020, 578, 409-412. [CrossRef] [PubMed]

68. Guo, X.; Shen, Y.; Liu, W.; Chen, D.; Liu, J. Estimation and Prediction of Industrial VOC Emissions in Hebei Province, China. Atmosphere 2021, 12, 530. [CrossRef]

69. Günkaya, Z.; Özdemir, A.; Özkan, A.; Banar, M. Environmental Performance of Electricity Generation Based on Resources: A Life Cycle Assessment Case Study in Turkey. Sustainability 2016, 8, 1097. [CrossRef]

70. Gaffney, J.S.; Marley, N.A. In-Depth Review of Atmospheric Mercury: Sources, Transformations, and Potential Sinks. Energy Emiss. Control Technol. 2014, 2,1-21. [CrossRef]

71. Tian, H.Z.; Lu, L.; Cheng, K.; Hao, J.M.; Zhao, D.; Wang, Y.; Jia, W.X.; Qiu, P.P. Anthropogenic Atmospheric Nickel Emissions and Its Distribution Characteristics in China. Sci. Total Environ. 2012, 417-418, 148-157. [CrossRef]

72. Yu, C.H.; Huang, L.; Shin, J.Y.; Artigas, F.; Fan, Z. Characterization of Concentration, Particle Size Distribution, and Contributing Factors to Ambient Hexavalent Chromium in an Area with Multiple Emission Sources. Atmos. Environ. 2014, 94, 701-708. [CrossRef]

73. Jaishankar, M.; Tseten, T.; Anbalagan, N.; Mathew, B.B.; Beeregowda, K.N. Toxicity, Mechanism and Health Effects of Some Heavy Metals. Interdiscip. Toxicol. 2014, 7, 60-72. [CrossRef]

74. National Center for Biotechnology Information. PubChem Compound Summary for CID 12749, 2-Methylimidazole. 2021. Available online: https:/ / pubchem.ncbi.nlm.nih.gov / compound/2-Methylimidazole (accessed on 1 June 2021).

75. National Center for Biotechnology Information. PubChem Compound Summary for CID 6228, N,N-Dimethylformamide. 2021. Available online: https:/ / pubchem.ncbi.nlm.nih.gov/compound/N_N-Dimethylformamide (accessed on 1 June 2021).

76. National Center for Biotechnology Information. PubChem Compound Summary for CID 887, Methanol. 2021. Available online: https: / / pubchem.ncbi.nlm.nih.gov/ compound/Methanol (accessed on 1 June 2021).

77. National Center for Biotechnology Information. PubChem Compound Summary for CID 15865313, Zinc Nitrate Hexahydrate. 2021. Available online: https:/ / pubchem.ncbi.nlm.nih.gov/compound/Zinc-nitrate-hexahydrate (accessed on 1 June 2021).

78. National Center for Biotechnology Information. PubChem Compound Summary for CID 23994, Zinc. 2021. Available online: https:/ / pubchem.ncbi.nlm.nih.gov/ compound/Zinc (accessed on 1 June 2021).

79. Liu, T.; Zhu, L.; Wang, J.; Wang, J.; Zhang, J.; Sun, X.; Zhang, C. Biochemical Toxicity and DNA Damage of Imidazolium-Based Ionic Liquid with Different Anions in Soil on Vicia Faba Seedlings. Sci. Rep. 2015, 5, 18444. [CrossRef]

80. Zhang, C.; Zhu, L.; Wang, J.; Wang, J.; Zhou, T.; Xu, Y.; Cheng, C. The Acute Toxic Effects of Imidazolium-Based Ionic Liquids with Different Alkyl-Chain Lengths and Anions on Zebrafish (Danio Rerio). Ecotoxicol. Environ. Saf. 2017, 140, 235-240. [CrossRef]

81. Romero, A.; Santos, A.; Tojo, J.; Rodríguez, A. Toxicity and Biodegradability of Imidazolium Ionic Liquids. J. Hazard. Mater. 2008, 151, 268-273. [CrossRef]

82. European Chemicals Agency. Zinc Nitrate. Available online: https://echa.europa.eu/el/substance-information/-/ substanceinfo/100.029.039 (accessed on 1 June 2021). 
83. Bozzano, G.; Manenti, F. Efficient Methanol Synthesis: Perspectives, Technologies and Optimization Strategies. Prog. Energy Combust. Sci. 2016, 56, 71-105. [CrossRef]

84. Kaviraj, A.; Bhunia, F.; Saha, N.C. Toxicity of Methanol to Fish, Crustacean, Oligochaete Worm, and Aquatic Ecosystem. Int. J. Toxicol. 2004, 23, 55-63. [CrossRef] [PubMed]

85. Yadav, P.; Athanassiadis, D.; Yacout, D.M.M.; Tysklind, M.; Upadhyayula, V.K.K. Environmental Impact and Environmental Cost Assessment of Methanol Production from Wood Biomass. Environ. Pollut. 2020, 265, 114990. [CrossRef]

86. Renó, M.L.G.; Lora, E.E.S.; Palacio, J.C.E.; Venturini, O.J.; Buchgeister, J.; Almazan, O. A LCA (Life Cycle Assessment) of the Methanol Production from Sugarcane Bagasse. Energy 2011, 36, 3716-3726. [CrossRef]

87. Najser, J.; Buryan, P.; Skoblia, S.; Frantik, J.; Kielar, J.; Peer, V. Problems Related to Gasification of Biomass—Properties of Solid Pollutants in Raw Gas. Energies 2019, 12, 963. [CrossRef]

88. Legislative Train Schedule. Available online: https:/ / www.europarl.europa.eu/legislative-train (accessed on 19 July 2021).

89. Ren, S.; Li, C.; Tan, Z.; Hou, Y.; Jia, S.; Cui, J. Carbonic Anhydrase@ZIF-8 Hydrogel Composite Membrane with Improved Recycling and Stability for Efficient $\mathrm{CO}_{2}$ Capture. J. Agric. Food Chem. 2019, 67, 3372-3379. [CrossRef]

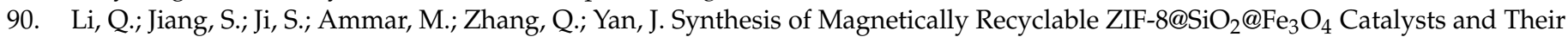
Catalytic Performance for Knoevenagel Reaction. J. Solid State Chem. 2015, 223, 65-72. [CrossRef]

91. Keser Demir, N.; Topuz, B.; Yilmaz, L.; Kalipcilar, H. Synthesis of ZIF-8 from Recycled Mother Liquors. Microporous Mesoporous Mater. 2014, 198, 291-300. [CrossRef]

92. Li, Y.; Ma, C.; Nian, P.; Liu, H.; Zhang, X. Green Synthesis of ZIF-8 Tubular Membranes from a Recyclable 2-Methylimidazole Water-Solvent Solution by ZnO Nanorods Self-Converted Strategy for Gas Separation. J. Membr. Sci. 2019, 581, 344-354. [CrossRef] 